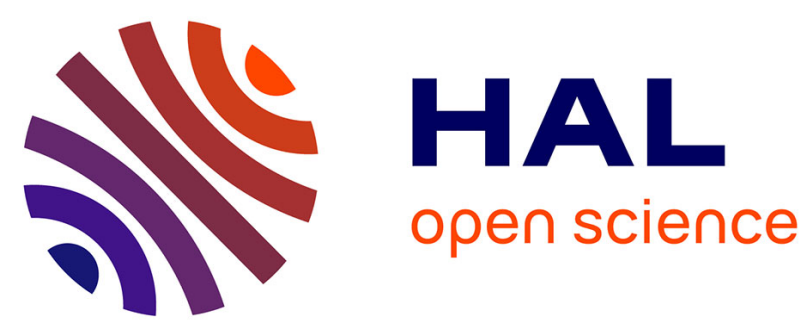

\title{
Comb-Like Fluorophilic-Lipophilic-Hydrophilic Polymers for Nanocapsules as Ultrasound Contrast Agents
}

Sophie Houvenagel, Laurence Moine, Guilherme Picheth, Camille Dejean, Annie Brûlet, Alexis Chennevière, Vincent Faugeras, Nicolas Huang, Olivier Couture, Nicolas Tsapis

\section{To cite this version:}

Sophie Houvenagel, Laurence Moine, Guilherme Picheth, Camille Dejean, Annie Brûlet, et al.. CombLike Fluorophilic-Lipophilic-Hydrophilic Polymers for Nanocapsules as Ultrasound Contrast Agents.

Biomacromolecules, 2018, 19 (8), pp.3244-3256. 10.1021/acs.biomac.8b00506 . hal-02323756

\section{HAL Id: hal-02323756 https://hal.science/hal-02323756}

Submitted on 22 Oct 2019

HAL is a multi-disciplinary open access archive for the deposit and dissemination of scientific research documents, whether they are published or not. The documents may come from teaching and research institutions in France or abroad, or from public or private research centers.
L'archive ouverte pluridisciplinaire HAL, est destinée au dépôt et à la diffusion de documents scientifiques de niveau recherche, publiés ou non, émanant des établissements d'enseignement et de recherche français ou étrangers, des laboratoires publics ou privés. 


\section{Comb-like fluorophilic-lipophilic-hydrophilic}

\section{2 polymers for nanocapsules as ultrasound contrast}

\section{3 agents}

4 Sophie Houvenagel ${ }^{a}$, Laurence Moine ${ }^{a}$, Guilherme Picheth ${ }^{a}$, Camille Dejean $^{b}$, Annie Brûlet $^{c}$,

5 Alexis Chennevière ${ }^{c}$, Vincent Faugeras $^{d}$, Nicolas Huang $^{a}$, Olivier Couture ${ }^{d}$, Nicolas Tsapis ${ }^{a} *$

6 a Institut Galien Paris-Sud, CNRS, Univ. Paris-Sud, Université Paris-Saclay, 92296 Châtenay-

7 Malabry, France

$8 \quad$ b BioCIS, CNRS, Univ. Paris-Sud, Université Paris-Saclay, 92296 Châtenay-Malabry, France

$9{ }^{\mathrm{c}}$ Laboratoire Léon Brillouin, UMR12 CEA-CNRS, CEA Saclay, Gif sur Yvette, F-91191,

10 France

11 d Institut Langevin, ESPCI Paris, CNRS (UMR 7587), INSERM (U979), Paris, France

12

13 * Corresponding authors at: CNRS, Institut Galien Paris-Sud, CNRS UMR 8612, Faculté de 14 Pharmacie, 92296 Châtenay-Malabry, France. E-mail address: laurence.moine@u-psud.fr 15 (Laurence Moine) and nicolas.tsapis@u-psud.fr (Nicolas Tsapis)

$17 \quad$ Keywords

18 Comb-like fluorinated polymers; fluorous interactions; nanocapsules; perfluorocarbons;

19 ultrasound contrast agents 
Imaging the enhanced permeation and retention effect by ultrasound is hindered by the large size of commercial ultrasound contrast agents (UCAs). To obtain nanosized UCAs, triblock copolymers of poly(ethylene glycol)-polylactide-poly $(1 \mathrm{H}, 1 \mathrm{H}, 2 \mathrm{H}, 2 \mathrm{H}$-heptadecafluorodecyl methacrylate) (PEG-PLA-PFMA) with distinct numbers of perfluorinated pendant chains (5, 10 or 20) are synthesized by a combination of ring-opening polymerization and atom transfer radical polymerization. Nanocapsules (NCs) containing perfluorooctyl bromide (PFOB) intended as UCAs are obtained with a 2-fold increase in PFOB encapsulation efficiency in fluorinated NCs as compared to plain PEG-PLA NCs thanks to fluorous interactions. NC morphology is strongly influenced by the number of perfluorinated chains and the amount of

31 polymer used for formulation, leading to peculiar capsules with several PFOB cores at high 32 PEG-PLA-PFMA 20 amount and single-cored NCs with a thinner shell at low fluorinated polymer amount, as confirmed by small angle neutron scattering. Finally, fluorinated NCs

34 yield higher in vitro ultrasound signal compared to PEG-PLA NCs and no in vitro cytotoxicity is induced by fluorinated polymers and their degradation products. Our results highlight the benefit of adding comb-like fluorinated blocks in PEG-PLA polymers to modify the nanostructure and enhance the echogenicity of nanocapsules intended as UCAs. 


\section{Introduction}

41 Ultrasound is one of the most widely used clinical imaging modality owing to its low cost, safety, portability, and possible combination with therapy. ${ }^{1}$ Nevertheless, this technique has been limited by the lack of effective ultrasound contrast agents (UCAs) to allow tissue differentiation. ${ }^{2,3}$ Commercially available UCAs consist of $1-6 \mu \mathrm{m}$ gas microbubbles stabilized by a layer of lipids or proteins. ${ }^{4,5}$ Their large size and high compressibility make them ideal ultrasound reflectors, currently used to enhance the blood pool signal and assess tissue blood flow at the microvascular level. ${ }^{6}$ However, the fast diffusion of the encapsulated gas results in short circulation time in the bloodstream (a few minutes), ${ }^{7}$ and their large micrometer size prevents their accumulation in solid tumors. For tumor imaging, more stable nano-sized UCAs able to extravasate into tumors by the enhanced permeation and retention (EPR) effect $^{8}$ are required. Since gas nanobubbles are difficult to stabilize, ${ }^{9}$ research has focused on the encapsulation of liquid perfluorocarbons. ${ }^{10}$ To further improve UCAs stability, several groups have reported the use of polymeric shells which are more stable than lipid or protein layers. $^{11-14}$

In this context, polymeric UCAs have been developed recently in our group. These polymeric nanocapsules (NCs) of poly(lactide-co-glycolide) (PLGA) encapsulating liquid perfluorooctyl bromide (PFOB) showed long-lasting in vitro echogenicity and allowed in vivo blood pool imaging. ${ }^{15}$ However, quick elimination by the mononuclear phagocyte system hampered their accumulation in the tumor. PLGA was then replaced by poly(lactide-co-glycolide)poly(ethylene glycol) (PLGA-PEG) copolymer to formulate long-circulating NCs which accumulated in the tumor by the EPR effect, and yielded contrast enhancement by ${ }^{19} \mathrm{~F}$ Magnetic Resonance Imaging. ${ }^{16}$ Nevertheless, the acoustic response of these capsules remained too weak at clinical frequencies, owing mainly to the important thickness of their shells. The strategy of decreasing the polymer amount in the formulation, which previously 
65 allowed reducing the thickness of plain PLGA NCs, ${ }^{17}$ failed using PLGA-PEG due to local 66 dewetting. ${ }^{18}$

67 Our aim is therefore to improve the nanocapsule echogenicity by reducing their shell 68 thickness, while keeping their long-circulating properties with PEG chains. Recently, we reported that functionalizing PLA with a short linear perfluorinated end group induced an increase of PFOB encapsulation efficiency into PEGylated NCs made of a mixture of PLAPEG and fluorinated-PLA, for perfluorinated chain length up to $\mathrm{C}_{8} \mathrm{~F}_{17}{ }^{19}$ However, the shell thickness was not reduced, and although a higher in vitro echogenicity was obtained due to fluorination, there is still room for improvement since the ultrasound signal was much lower than commercial Sonovue microbubbles.

Plenty of reports on different triblock copolymers with hydrophilic, hydrophobic, and fluorinated blocks exist and nanoparticles formed using these polymers exhibit different morphologies. $^{20-24}$ Here, the strategy consists in synthesizing triblock hydrophilichydrophobic-fluorophilic copolymers of poly(ethylene glycol)-polylactidepoly $(1 \mathrm{H}, 1 \mathrm{H}, 2 \mathrm{H}, 2 \mathrm{H}-$ heptadecafluorodecyl methacrylate) (PEG-PLA-PFMA), containing a higher proportion of $\mathrm{C}_{8} \mathrm{~F}_{17}$ chains, to formulate nanocapsules. We intend to favor fluorous

81 interactions between the fluorinated chains and PFOB to improve the wetting of the polymer around the PFOB core and yield capsules with thin shells as we decrease the amount of polymer in the formulation. We present here the polymer synthesis and the characterization of nanocapsules in terms of size distribution, morphology, PFOB encapsulation efficiency, shell thickness as measured by Small Angle Neutron Scattering, cytotoxicity and in vitro ultrasound scattering. 
2.1. Materials

DL-lactide was purchased from Biovalley, Polysciences Inc. (USA). Poly(ethylene glycol) methyl ether (OH-PEG-OCH 3 , average $\left.M_{n}=5000 \mathrm{~g} / \mathrm{mol}\right)$, stannous 2-ethyl hexanoate

(stannous octoate, $\left.\mathrm{Sn}(\mathrm{Oct})_{2}\right), \mathrm{N}, \mathrm{N}, \mathrm{N}^{\prime}, \mathrm{N}^{\prime \prime}, \mathrm{N}^{\prime \prime}$-pentamethyldiethylenetriamine (PMDETA), triethylamine $\left(\mathrm{Et}_{3} \mathrm{~N}\right)$, dried toluene, cyclohexanone, magnesium sulfate $\left(\mathrm{MgSO}_{4}\right)$, sodium cholate, $\mathrm{D}_{2} \mathrm{O}$ and trifluoroacetic acid (TFA) were provided by Sigma-Aldrich (France). 1H,1H,2H,2H-heptadecafluorodecyl methacrylate (FMA) and perfluorooctyl bromide (PFOB) were purchased from Fluorochem (UK). 2-Bromo-2-methylpropionyl bromide and copper(I) bromide $(\mathrm{CuBr})$ were provided by ACROS Organics (Belgium). Deuterated chloroform $\left(\mathrm{CDCl}_{3}\right)$ was obtained from Euriso-top (France). All solvents were purchased from Carlo Erba (France). Cell culture reagents such as DMEM (Dulbecco's modified Eagle's medium), RPMI 1640 (Roswell Park Memorial Institute medium), FBS (Fetal Bovine Serum), trypsin-EDTA solution and PBS $\left(\mathrm{Ca}^{2+}\right.$ and $\mathrm{Mg}^{2+}$ free phosphate buffer) were purchased from Sigma Aldrich (France). Water was purified using a RIOS/Synergy system from Millipore (France). NMR sample tubes and coaxial inserts were obtained from CortecNet (France).

\subsection{Polymer synthesis}

The synthesis route involved 3 steps as shown in Figure 1.

\subsubsection{Synthesis of PEG-PLA}

PEG-PLA was synthesized by ring-opening polymerization (ROP) of DL-lactide initiated by OH-PEG-OCH$H_{3}$ in the presence of stannous octoate catalyst. ${ }^{25}$ All glassware was dried by heating under vacuum and handled under argon atmosphere. To a $250 \mathrm{~mL}$ round-bottom flask equipped with a magnetic stir-bar were added DL-lactide (156.14 mmol, $22.50 \mathrm{~g})$ and $\mathrm{OH}-$ PEG-OCH 3 (1.13 mmol, $5.66 \mathrm{~g})$. The flask was sealed with a rubber cap and a stannous 
112 octoate solution $(0.75 \mathrm{mmol}, 306 \mathrm{mg})$ dissolved in $30 \mathrm{~mL}$ of dried toluene was added through

113 the septum. The tube was purged with argon for 15 minutes and then placed into a $130^{\circ} \mathrm{C}$ oil

114 bath. Polymerization was carried out for $1 \mathrm{~h}$ under magnetic stirring, and then quenched by

115 immersing the tube in a cold water bath. After evaporation of toluene, the reaction product

116 was dissolved in chloroform and precipitated twice into excess cold diethyl ether. The

117 polymer was finally dried under vacuum and $25.13 \mathrm{~g}$ of a white powder was obtained. Lactide

118 conversion $=94 \%\left({ }^{1} \mathrm{H}\right.$ NMR $) .{ }^{1} \mathrm{H}$ NMR $\left(300 \mathrm{MHz}, \mathrm{CDCl}_{3}, \delta, \mathrm{ppm}\right): 5.10-5.28\left(\mathrm{CHCH}_{3} \mathrm{COO}\right.$

119 of PLA), $3.64\left(\mathrm{OCH}_{2} \mathrm{CH}_{2}\right.$ of PEG), 3.38 ( $\mathrm{OCH}_{3}$ of PEG), 2.70 (end $\mathrm{HOCHCH}_{3} \mathrm{COO}$ of PLA),

$1201.45-1.67\left(\mathrm{CHCH}_{3} \mathrm{COO}\right.$ of PLA $) \cdot M_{n}^{\mathrm{NMR}}=23,500 \mathrm{~g} / \mathrm{mol} ; M_{n}^{\mathrm{SEC}}=24,300 \mathrm{~g} / \mathrm{mol}$.

2.2.2. Synthesis of PEG-PLA-Br macroinitiator

122

123

124

125

126

PEG-PLA-Br was synthesized by esterification of PEG-PLA with excess 2-Bromo-2methylpropionyl bromide using a known procedure. ${ }^{26,27}$ In a $250 \mathrm{~mL}$ round-bottom flask equipped with a magnetic stir-bar, PEG-PLA (1.06 mmol, $25 \mathrm{~g})$ was dissolved in $160 \mathrm{~mL}$ of $\mathrm{CH}_{2} \mathrm{Cl}_{2}$. Excess of triethylamine $(37.23 \mathrm{mmol}, 5.2 \mathrm{~mL})$ was added to the solution, and the mixture was stirred under argon and cooled to $0^{\circ} \mathrm{C}$ with an ice bath. 2-Bromo-2methylpropionyl bromide $(37.23 \mathrm{mmol}, 4.6 \mathrm{~mL})$ was added dropwise for $15 \mathrm{~min}$. The mixture was allowed to stir at room temperature overnight, and was subsequently washed twice with saturated brine and once with water. The organic phase was dried over anhydrous $\mathrm{MgSO}_{4}$ before being concentrated under reduced pressure and precipitated twice in excess cold diethyl ether. The product was finally dried under vacuum to provide $16.55 \mathrm{~g}$ of an off-white solid. ${ }^{1} \mathrm{H}$ NMR $\left(300 \mathrm{MHz}, \mathrm{CDCl}_{3}, \delta, \mathrm{ppm}\right): 5.10-5.28\left(\mathrm{CHCH}_{3} \mathrm{COO}\right.$ of PLA), 3.64 $\left(\mathrm{OCH}_{2} \mathrm{CH}_{2}\right.$ of $\left.\mathrm{PEG}\right), 3.38\left(\mathrm{OCH}_{3}\right.$ of $\left.\mathrm{PEG}\right), 1.95$ and $1.98\left(\mathrm{C}(\mathrm{Br})\left(\mathrm{CH}_{3}\right)_{2}\right), 1.45-1.67$ $\left(\mathrm{CHCH}_{3} \mathrm{COO}\right.$ of PLA $) . M_{n}{ }^{\mathrm{NMR}}=23,500 \mathrm{~g} / \mathrm{mol} ; M_{n}{ }^{\mathrm{SEC}}=25,200 \mathrm{~g} / \mathrm{mol}$. 
136 PEG-PLA-PFMA $\mathrm{x}_{\mathrm{x}}$ polymers were synthesized by ATRP of $1 \mathrm{H}, 1 \mathrm{H}, 2 \mathrm{H}, 2 \mathrm{H}-$ 137 heptadecafluorodecyl methacrylate (FMA) initiated by PEG-PLA-Br with CuBr/PMDETA as

138 the catalyst system. ${ }^{28}$ All glassware was dried by heating under vacuum and handled under 139 argon atmosphere. To a $100 \mathrm{~mL}$ round-bottom flask equipped with a magnetic stir-bar were 140 added PEG-PLA-Br (0.21 mmol, $5 \mathrm{~g})$ and a solution of PMDETA (0.21 mmol, $37 \mathrm{mg})$ and 141 FMA (1.06 mmol for $\mathrm{x}=5,2.13 \mathrm{mmol}$ for $\mathrm{x}=10,4.26 \mathrm{mmol}$ for $\mathrm{x}=20)$ in cyclohexanone 142 (15 mL). After dissolution of the macroinitiator, $\mathrm{CuBr}(0.21 \mathrm{mmol}, 31 \mathrm{mg})$ was added and the 143 mixture was subjected to two freeze-pump-thaw cycles. The reaction proceeded at $100{ }^{\circ} \mathrm{C}$ for 144 42h. The mixture was cooled and diluted with THF, and the copper catalyst was removed with 145 a neutral alumina column. After concentration under reduced pressure, the product was 146 precipitated twice in excess cold diethyl ether and dried under vacuum. FMA conversion $\left({ }^{1} \mathrm{H}\right.$ $\mathrm{NMR})=84 \%(\mathrm{x}=20), 80 \%(\mathrm{x}=10), 67 \%(\mathrm{x}=5) .{ }^{1} \mathrm{H} \mathrm{NMR}\left(300 \mathrm{MHz}, \mathrm{CDCl}_{3}, \delta, \mathrm{ppm}\right):$ 5.10-5.28 $\left(\mathrm{CHCH}_{3} \mathrm{COO}\right.$ of PLA), $4.28\left(\mathrm{OCH}_{2} \mathrm{CH}_{2} \mathrm{CF}_{2}\right.$ of PFMA), 3.64 ( $\mathrm{OCH}_{2} \mathrm{CH}_{2} \mathrm{O}$ of PEG), 3.38 (end $\mathrm{OCH}_{3}$ of PEG), $2.47\left(\mathrm{OCH}_{2} \mathrm{CH}_{2} \mathrm{CF}_{2}\right.$ of PFMA), 1.70-2.00 $\left(\mathrm{CH}_{2} \mathrm{C}\left(\mathrm{CH}_{3}\right) \mathrm{COO}\right.$ of PFMA), 1.45-1.67 ( $\mathrm{CHCH}_{3} \mathrm{COO}$ of PLA), 0.80-1.45 $\left(\mathrm{CH}_{2} \mathrm{C}\left(\mathrm{CH}_{3}\right) \mathrm{COO}\right.$ of PFMA). Molar 151 masses are displayed in Table 1.

\subsection{Polymer characterization}

153 Size exclusion chromatography (SEC) was performed at $30{ }^{\circ} \mathrm{C}$ with two columns from 154 Polymer Laboratories (PL-gel MIXED-D; $300 \times 7.5 \mathrm{~mm}$ ) and a differential refractive index 155 detector (Spectrasystem RI-150, Thermo Electron Corp.), using chloroform as an eluent, a 156 Waters 515 pump at a flow rate of $1 \mathrm{~mL} / \mathrm{min}$, and toluene as a flow-rate marker. The 157 polymers were dissolved at $5 \mathrm{mg} / \mathrm{mL}$ in the eluent and filtered on $0.2 \mu \mathrm{m}$ PTFE syringe filters 158 prior to injection. The calibration curve was based on poly(methyl methacrylate) (PMMA) 159 standards from Polymer Laboratories. ${ }^{1} \mathrm{H}$ NMR and ${ }^{19} \mathrm{~F}$ NMR spectroscopies were performed 
160 in $5 \mathrm{~mm}$ diameter tubes in $\mathrm{CDCl}_{3}$ on a Bruker Avance-400 (400 MHz) spectrometer. The DP

161 and $M_{\mathrm{n}}$ of the commercial $\mathrm{OH}-\mathrm{PEG}-\mathrm{OCH}_{3}$ were confirmed by ${ }^{1} \mathrm{H} \mathrm{NMR}$ in $\mathrm{CDCl}_{3}$ using the 162 ratio of the methyl signal at $3.38 \mathrm{ppm}$ versus the main chain signal at $3.64 \mathrm{ppm}$ : DP $=118, M_{\mathrm{n}}$

$163=5.2 \times 10^{3} \mathrm{~g} / \mathrm{mol}$. Differential scanning calorimetry (DSC) was performed using a DSC Q1000

164 (TA Instruments). The polymers $(2-5 \mathrm{mg})$ were sealed in aluminum pans and heated from -20

165 to $100^{\circ} \mathrm{C}$ at a heating rate of $20^{\circ} \mathrm{C} / \mathrm{min}$ and cooled to $-20{ }^{\circ} \mathrm{C}$ before a second heating scan

166 from -20 to $100^{\circ} \mathrm{C}$ at $20^{\circ} \mathrm{C} / \mathrm{min}$ to determine the glass transition temperature $\left(T_{g}\right)$. A nitrogen

167 flow was maintained throughout the test $(20 \mathrm{~mL} / \mathrm{min})$.

\subsection{Interfacial tension measurements}

169 Interfacial tension measurements were carried out using the pendant drop method, employing

170 a Tracker tensiometer (Teclis, France). Drops of PFOB were formed using a syringe and a

171 G22 stainless steel needle into a methylene chloride solution containing the polymers at 25

$172 \mathrm{mg} / \mathrm{mL}$ placed in an optical glass cuvette. The interfacial tension was determined from the

173 drop profile using the Laplace equation and the forces balance between capillarity and

174 gravity. The measurements were performed on at least three independent drops and the

175 experiment was repeated on different days to ensure reproducibility.

\subsection{Nanocapsules preparation}

177 Nanocapsules (NCs) of PFOB were prepared by an emulsion-evaporation process as 178 previously described. ${ }^{16,19}$ The polymer $(50,30$ or $20 \mathrm{mg}$ ) was dissolved into $2 \mathrm{~mL}$ of 179 methylene chloride along with $30 \mu \mathrm{L}$ of PFOB. The organic phase was emulsified into $10 \mathrm{~mL}$ 180 of $1.5 \%$ sodium cholate $(\mathrm{w} / \mathrm{v})$ aqueous solution using a vortex for $1 \mathrm{~min}$ and then a vibrating 181 metallic tip (Digital Sonifier, Branson Ultrasons, France) at 30\% of maximal power, for 1 min

182 over ice. Solvent was allowed to evaporate by magnetic stirring at $300 \mathrm{rpm}$ at room 183 temperature for $3 \mathrm{~h}$. Suspensions of NCs were filtered through $0.45 \mu \mathrm{m}$ PVDF filters, and if 
necessary, were purified to remove sodium cholate by ultracentrifugation for $1 \mathrm{~h}$, at $4{ }^{\circ} \mathrm{C}$ and at $27440 \mathrm{~g}$ (Optima LE-80K Ultracentrifuge Beckman Coulter). The pellet was finally resuspended in water to the desired concentration.

\subsection{Size distribution and Zeta potential}

The hydrodynamic diameter $\left(d_{\mathrm{H}}\right)$ and polydispersity index (PDI) of the nanocapsules were

189 measured by quasi-elastic light scattering, using a Zetasizer Nano ZS instrument (Malvern,

190 France). Suspensions were diluted in water to a concentration of $1 \mathrm{mg} / \mathrm{mL}$. Measurements

191 were performed at $20^{\circ} \mathrm{C}$, at an angle of $173^{\circ}$ to avoid multiple scattering. Zeta potential

192 measurements were carried out with the same instrument, at $25^{\circ} \mathrm{C}$, in $1 \mathrm{mM} \mathrm{NaCI}$.

193 Measurements were performed in triplicate.

195 PFOB encapsulation efficiency was determined by ${ }^{19} \mathrm{~F}$ NMR on a Bruker Avance-400 (400

$196 \mathrm{MHz}$ ) spectrometer with a $5 \mathrm{~mm}$ dual probe ${ }^{19} \mathrm{~F} /{ }^{1} \mathrm{H}$. The NMR quantitative method using stem

197 coaxial inserts was originally proposed by Henderson for ${ }^{31} \mathrm{P}$ compounds ${ }^{29}$ and adapted

198 previously for ${ }^{19} \mathrm{~F}$ NMR. ${ }^{30,19} 1 \mathrm{~mL}$ of unpurified nanocapsules were freeze-dried for $24 \mathrm{~h}$

199 using an Alpha-1-2 LD apparatus (Christ, France) and lyophilisates were dissolved into $1 \mathrm{~mL}$

200 of chloroform. Sodium cholate was removed by centrifugation for $5 \mathrm{~min}$ at $4696 \mathrm{~g}$. The

201 organic solution was collected and introduced into a usual 5mm-NMR sample tube loaded

202 with a stem coaxial insert containing TFA in $\mathrm{D}_{2} \mathrm{O}$ as an external standard ([TFA] $=9.4$

$203 \mu$ mol.mL $L^{-1}$ ). The total amount of PFOB in the suspension, $n_{P F O B}$, was determined after

204 integration of the peak at $-64.7 \mathrm{ppm}$ corresponding to the $\mathrm{CF}_{2} \mathrm{Br}$ group and normalization by

205 the area of the TFA peak at $-76.5 \mathrm{ppm}$. Absolute encapsulation efficiency, $\eta_{\text {encaps }}$, was 206 calculated as follows: 


$$
\eta_{\text {encaps }}=\frac{n_{P F O B}}{n_{P F O B}^{m a x}} \text { with } n_{P F O B}^{\max }=\frac{m_{P F O B}^{f e e d}}{M_{P F O B}} \frac{m_{N C}}{m_{P F O B}^{f e e d}+m_{\text {polymer }}^{f e e d}+m_{S C}^{f e e d}}
$$

208 where $m_{P F O B}^{f e e d}, m_{\text {polymer }}^{\text {feed }}$ and $m_{S C}^{\text {feed }}$ are the initial masses of the components introduced during 209 NCs preparation, $m_{N C}$ corresponds to the mass of NCs recovered after freeze-drying and $210 \quad M_{P F O B}$ is the molar mass of PFOB $(498.96 \mathrm{~g} / \mathrm{mol})$.

\subsection{Transmission electron microscopy (TEM)}

212 TEM was performed at I2BC (Gif-sur-Yvette, France) using a JEOL JEM-1400 operating at $21380 \mathrm{kV} .5 \mu \mathrm{L}$ of purified suspensions of nanocapsules $(0.5 \mathrm{mg} / \mathrm{mL})$ were deposited for $1 \mathrm{~min}$ 214 on glow-discharged copper grids covered with formvar-carbon film. Samples were then 215 stained using $2 \%$ phosphotungstic acid $(\mathrm{pH}=7)$ for $30 \mathrm{~s}$. The excess solution was blotted off 216 using a filter paper. Images were acquired using an Orius camera (Gatan Inc, USA).

\subsection{Cryo-transmission electron microscopy (cryoTEM)}

218 CryoTEM was performed at I2BC (Gif-sur-Yvette, France) using a JEOL JEM-1400 219 operating at $120 \mathrm{kV} .5 \mu \mathrm{L}$ of purified suspensions of nanocapsules $(25 \mathrm{mg} / \mathrm{mL})$ were 220 deposited on glow-discharged Lacey copper grids covered with carbon film containing holes.

221 The excess solution was blotted off for $5 \mathrm{~s}$ using filter paper and the grids were subsequently 222 frozen in liquid ethane using a Leica EM GP automatic system (Leica, Austria) under a 90\% 223 humidity atmosphere. Images were recorded on a US1000XP camera (Gatan Inc, USA) with a $224-2 \mu \mathrm{m}$ defocus.

2.10. Small angle neutrons scattering (SANS)

\subsubsection{SANS data collection}

227 Small Angle Neutron Scattering (SANS) measurements were performed on the PACE 228 spectrometer of the Laboratoire Léon Brillouin (LLB, CEA-Saclay, France). Nanocapsules 
were filtered, purified and resuspended at a final volume fraction of $\varphi_{\mathrm{v}}=1 \%$ in a $40 / 60(\mathrm{v} / \mathrm{v})$

$\mathrm{H}_{2} \mathrm{O} / \mathrm{D}_{2} \mathrm{O}$ mixture to match the scattering length density of the PFOB core $\left(\rho_{P F O B}=\rho_{\text {core }}=3.6\right.$

$\left.231 \times 10^{10} \mathrm{~cm}^{-2}\right)$. This mixture has a weak contrast with PFMA block polymer $\left(\rho_{P F M A}=3.0 \times 10^{10}\right.$

$232 \mathrm{~cm}^{-2}$ ). So, using contrast matching of the PFOB core, we focused on the polymeric shell of 233 PEG-PLA blocks. Two configurations were used: the first one with a sample-to-detector 234 distance of $\mathrm{D}=4.7 \mathrm{~m}$ and a neutron wavelength of $\lambda=13 \AA$ and the second one with $\mathrm{D}=2.9$ $235 \mathrm{~m}$ and $\lambda=4.6 \AA$ to cover a broad q range of $3.2 \times 10^{-3}-1.5 \times 10^{-1} \AA^{-1}$. SANS measurements 236 were performed in $1 \mathrm{~mm}$ thick quartz cuvettes to minimize the incoherent scattering. 237 Scattered intensity curves were corrected from the scattering from the empty quartz cuvette 238 and the electronic background, and normalized by the incoherent signal of $1 \mathrm{~mm}$ water sample 239 to account for non-uniform efficiency of detector, using the LLB PASINET software. ${ }^{31}$

The scattered intensity curves obtained in PFOB matching condition were fitted using the vesicle model with Sasview software. ${ }^{32}$ This model provides the form factor, $\mathrm{P}(\mathrm{q})$, for a unilamellar vesicle of inner radius $R_{\text {core }}$ and thickness T, according to the following equation:

$$
P(q)=\frac{\text { scale }}{V_{2}}\left[\frac{3 V_{1}\left(\rho_{1}-\rho_{2}\right) J_{1}\left(q R_{1}\right)}{q R_{1}}+\frac{3 V_{2}\left(\rho_{2}-\rho_{\text {solv }}\right) J_{1}\left(q R_{2}\right)}{q R_{2}}\right]^{2}
$$

244 Where scale is a scale factor, $V_{1}$ is the volume of the core, $V_{2}$ is the total volume of the 245 vesicle, $R_{1}=R_{\text {core }}$ is the radius of the core, $R_{2}$ is the outer radius of the vesicle $\left(R_{2}=R_{\text {core }}+\right.$ $246 \mathrm{~T})$, and $J_{1}(x)=\frac{\sin x-x \cos x}{x^{2}}$. For the vesicle, $\rho_{1}=\rho_{\text {core }}=\rho_{\text {solv }}$ is the scattering length density 247 of the core and the solvent, $\rho_{2}=\rho_{\text {shell }}$ is the scattering length density of the shell. The fit gives 248 geometrical parameters of the nanocapsules: the mean core radius $R_{\text {core, }}$, the polydispersity of 249 the core radius $\sigma_{\text {core, }}$, the thickness of the shell T and the polydispersity of the thickness $\sigma_{\mathrm{T}}$. A 250 lognormal distribution was assumed for both radius and thickness. 
2.11. Hydrolytic degradation of polymers

$25250 \mathrm{mg}$ of each polymer (except PEG-PLA-PFMA ${ }_{20}$ ) were suspended into $1 \mathrm{~mL}$ of $\mathrm{NaOH} 1 \mathrm{M}$ 253 and vigorously stirred for $24 \mathrm{~h}$ at $37^{\circ} \mathrm{C}$ in an incubator. After adjustment of the $\mathrm{pH}$ to 7 with $254 \mathrm{HCl} 1 \mathrm{M}$, the cloudy solution was dialyzed against deionized water for $96 \mathrm{~h}$ to remove salt and 255 lactic acid (dialysis membrane molecular weight cut off: 100-500 Da).

\subsection{Cell culture}

257 Human endothelial umbilical vein cells (HUVEC) obtained from ATCC (USA) were cultured in DMEM supplemented with $50 \mathrm{U} \cdot \mathrm{mL}^{-1}$ penicillin, $50 \mathrm{U} \cdot \mathrm{mL}^{-1}$ streptomycin, and $10 \%$ heat inactivated FBS. The J774.A1 murine macrophage monocyte cell line (ATCC, USA) was cultured in RPMI 1640 medium supplemented with $50 \mathrm{U} \cdot \mathrm{mL}^{-1}$ penicillin, $50 \mathrm{U} \cdot \mathrm{mL}^{-1}$ streptomycin, and 10\% heat inactivated FBS. Cells were split twice a week, by trypsinisation for HUVEC and by scraping for J774.A1 cells. All cell lines were maintained at $37{ }^{\circ} \mathrm{C}$ and $5 \% \mathrm{CO}_{2}$ under a humidified atmosphere.

\subsection{Cytotoxicity evaluation of NCs and polymer degradation products}

To evaluate their in vitro cytotoxicity, NCs and polymer degradation products were diluted in cell culture medium before being added onto the cells. The cell viability was evaluated using the 3-[4,5-dimethylthiazol-2-yl]-3,5-diphenyltetrazolium bromide (MTT) assay. Briefly, cells were seeded in $100 \mu \mathrm{L}$ of culture medium $\left(12 \times 10^{3}\right.$ cells/well or $3 \times 10^{3}$ cells/well for 24 and 72h incubation respectively) in 96 well plates (TPP, Switzerland) and pre-incubated for $24 \mathrm{~h}$.

$270100 \mu \mathrm{L}$ of a serial dilution of NCs $(0.01$ to $10 \mathrm{mg} / \mathrm{mL})$ or of polymer degradation products $271\left(10^{-5}\right.$ to $0.01 \mathrm{mg} / \mathrm{mL}$ of initial polymer $)$ was then added to the medium. After 24 or $72 \mathrm{~h}$ of 272 incubation, the incubation medium was replaced by fresh medium containing $0.5 \mathrm{mg} / \mathrm{mL}$ of 273 MTT (Sigma, France). After 1h incubation, the culture medium was gently aspirated and 274 replaced by $200 \mu \mathrm{L}$ dimethylsulfoxide (ACS grade, VWR, France) to dissolve the formazan 
crystals. The absorbance of the solubilized dye, which correlates with the number of living cells, was measured with a microplate reader (LAB Systems Original Multiscan MS, Finland) at $570 \mathrm{~nm}$. The percentage of viable cells in each well was calculated as the absorbance ratio between treated and untreated control cells.

\subsection{In vitro ultrasound measurements}

Suspensions of nanocapsules $(1 \mathrm{~mL}, 5 \mathrm{mg} / \mathrm{mL})$ were placed in a $10 \mathrm{~mm} \times 10 \mathrm{~mm} \times 45 \mathrm{~mm}$ polystyrene cuvette in which 5-mm diameter holes were cut out and covered by acoustically transparent mylar membrane, as shown in Figure S1. The cuvette was placed in a water bath at $37^{\circ} \mathrm{C}$, and a small magnetic bar allowed agitating gently the suspension without disturbing the signal. Measurements were performed after 4 minutes to allow temperature equilibration and removal of potential bubbles. A Handyscope HS5 (TiePie engineering, Netherlands) was used as both an arbitrary wave generator and a USB oscilloscope connected to a computer using Matlab (Mathworks, USA). Samples were insonified by a transducer (focal length 51 mm, model I3-0506-R-SU-F2.00IN, Olympus, France), which emitted 10 bursts of 500 cycles at $5 \mathrm{MHz}$. The scattered ultrasound signal was received by a second transducer (focal length $51 \mathrm{~mm}$, model I3-1506-R-SU-F2.00IN, Olympus, France) placed at a $90^{\circ}$ angle compared to the transducer-transmitter (Figure S1). This scattered signal was preamplified before being measured by the oscilloscope connected to Matlab for signal processing. The signal was then windowed, Fourier-transformed and the scattered intensity within the bandwidth of each harmonics was summed. The resulting ultrasound scattered intensities were subtracted from the intensity obtained with the cuvette filled with Milli-Q water. At least 9 measurements were performed with each sample. Commercial SonoVue ${ }^{\circledR}$ microbubbles (diluted to $1 / 1000$ ) were used as a reference positive control for the ultrasound set-up and parameters chosen for our study. 


\section{Results and discussion}

Triblock copolymers carrying perfluoroalkyl pendant chains were synthesized by a combination of ROP and ATRP as shown in Figure 1.

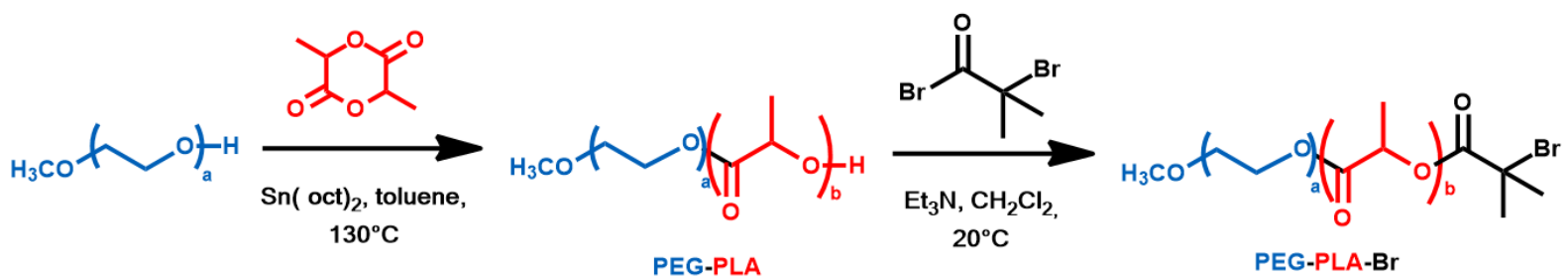

303

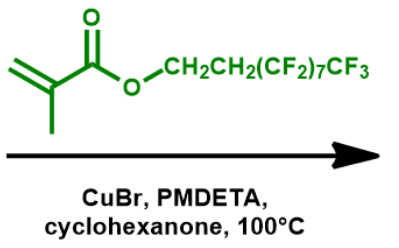
cyclohexanone, $100^{\circ} \mathrm{C}$

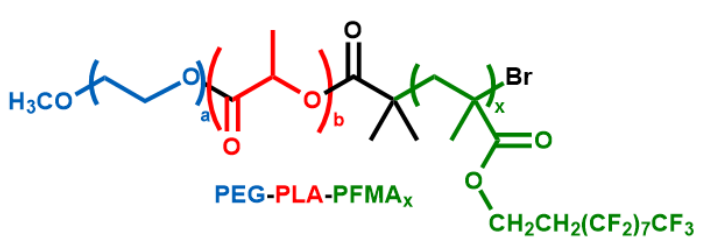

Figure 1. Synthesis of PEG-PLA-PFMA $A_{x}$ triblock copolymers.

ROP of D,L-lactide with polyethylene glycol methyl ether $\left(M_{n}=5,000 \mathrm{~g} / \mathrm{mol}\right)$ as initiator and $\mathrm{Sn}(\mathrm{oct})_{2}$ as catalyst first led to PEG-PLA diblock copolymer with molar mass close to the targeted $M_{n}$ of $25,000 \mathrm{~g} / \mathrm{mol}\left(M_{n}{ }^{\mathrm{NMR}}=23,500 \mathrm{~g} / \mathrm{mol}, M_{n}{ }^{\mathrm{SEC}}=25,500 \mathrm{~g} / \mathrm{mol}\right)$. PEG-PLA was subsequently converted to PEG-PLA-Br macroinitiator through esterification with excess 2bromo-2-methylpropionyl bromide in the presence of triethylamine. Quantitative conversion was confirmed by ${ }^{1} \mathrm{H}$ NMR with disappearance of the end hydroxyl broad signal of PLA at $2.70 \mathrm{ppm}$ and appearance of signals at 1.95 and $1.98 \mathrm{ppm}$ corresponding to the methyl protons from 2-bromo-2-methylpropionyl end group (supplementary material Figure S2).

The final PEG-PLA-PFMA ${ }_{x}$ copolymers were prepared by ATRP of FMA in cyclohexanone with PEG-PLA-Br as macroinitiator and $\mathrm{CuBr} / \mathrm{PMDETA}$ complex as catalyst. The nature and amount of solvent were initially varied to achieve final polymerization with satisfactory conversion $(>65 \%)$. Three different monomer/initiator feed molar ratios $(x=5,10,20)$ were 
used to design polymers with various fluorinated block lengths. Successful polymerization

318 was confirmed by ${ }^{1} \mathrm{H}$ NMR with appearance of the signals at 2.47 and $4.28 \mathrm{ppm}$ 319 corresponding respectively to $\mathrm{CH}_{2} \mathrm{CF}_{2}$ and $\mathrm{CH}_{2} \mathrm{CH}_{2} \mathrm{CF}_{2}$ protons of the PFMA block (signals $\mathrm{h}$ 320 and g, Figure 2), in addition to those of the methacrylate backbone $1.70-2.00$ and $0.80-$

3211.45 (signals e and f, Figure 2). The $4.28 \mathrm{ppm}$ peak area was used to calculate the copolymer 322 molar composition and molar mass by normalization with the $3.64 \mathrm{ppm}$ peak corresponding to 323 the $\mathrm{OCH}_{2} \mathrm{CH}_{2}$ of PEG (Table 1).

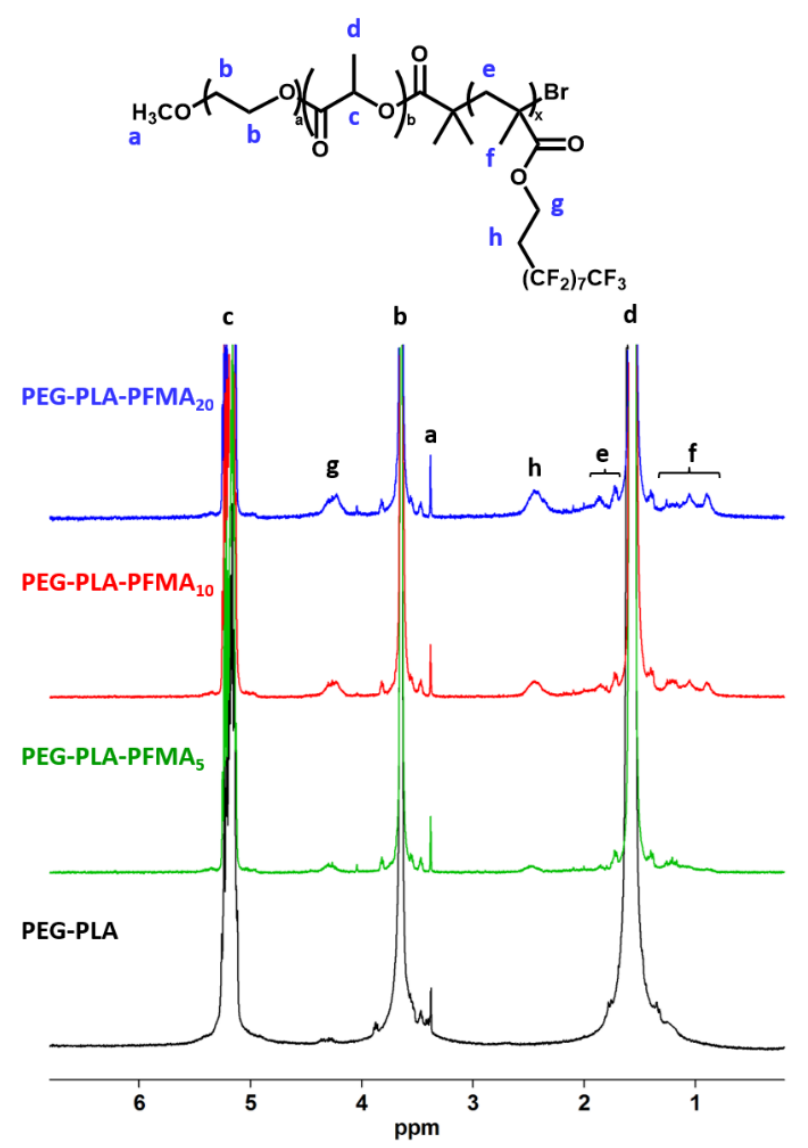

Figure 2. ${ }^{1} \mathrm{H}$ NMR spectra of PEG-PLA and triblock copolymers PEG-PLA-PFMA in $\mathrm{CDCl}_{3}$ (normalized with the PEG peak at $3.64 \mathrm{ppm}$ ).

${ }^{19} \mathrm{~F}$ NMR spectra of all polymers further support the successful polymerization of FMA 328 (Figure 3). A broadening of the fluorine resonances is observed in PEG-PLA-PFMA 5 spectrum as compared to the monomer. This effect is more pronounced as the number of 
330 perfluoroalkyl pendants increases, and leads to the overlapping of resonances of $\mathrm{CF}_{2}$ groups 331 b' in PEG-PLA-PFMA 10 and PEG-PLA-PFMA 20 spectra, in agreement with previous 332 reports. ${ }^{33,34}$ Moreover, a splitting of the peaks c' and d', corresponding to the $\mathrm{CF}_{2}$ and $\mathrm{CF}_{3}$ 333 groups at the extremity of the fluorinated pendants, is observed. This suggests the existence of 334 unaveraged conformations and therefore indicates some degree of self-association in 335 chloroform.
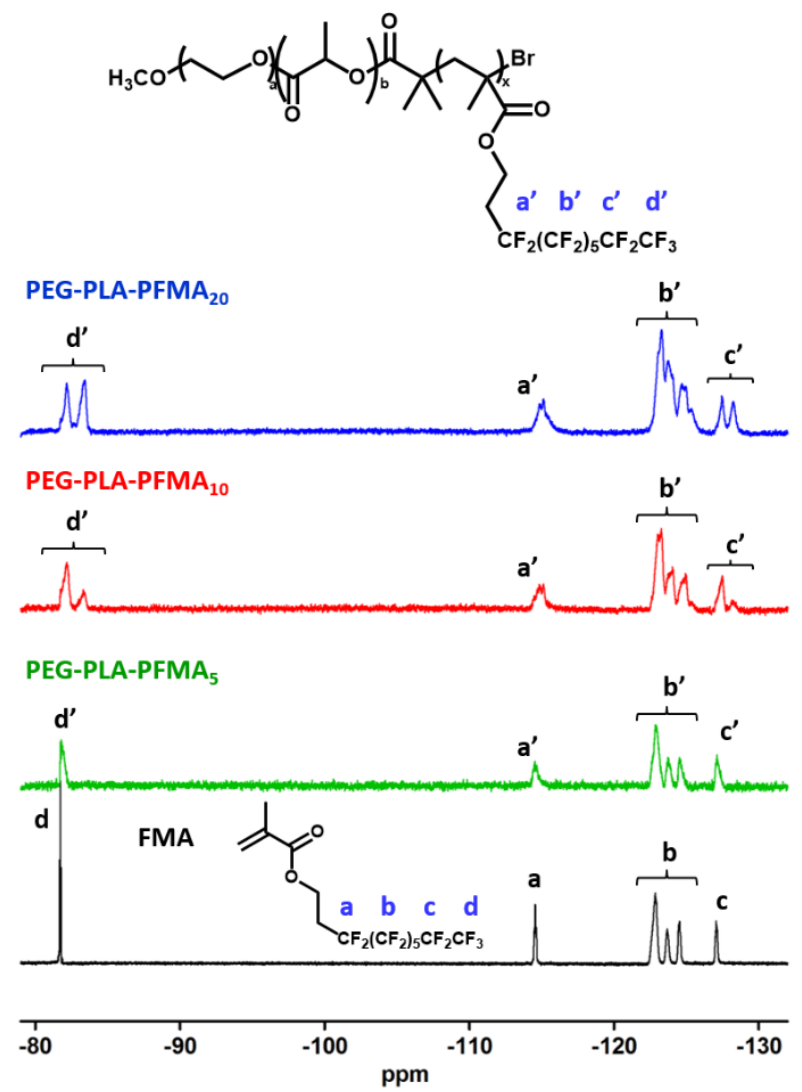

337 Figure 3. ${ }^{19}$ F NMR spectra of FMA (black line) and triblock copolymers PEG-PLA-PFMA in $\mathrm{CDCl}_{3}$.

339 The molar masses were also determined by conventional SEC in chloroform (Table 1). All 340 polymers present a single peak (supplementary material Figure S3), confirming the successful 341 formation of copolymers rather than homopolymer blends. Although $M_{n}^{\text {SEC }}$ values are close to $342 M_{n}^{\text {NMR }}$ values, $M_{n}^{\text {SEC }}$ does not increase with the polymerization degree of the PFMA block, as 343 shown by the superposition of chromatograms and the values in the $24,000-26,500 \mathrm{~g} / \mathrm{mol}$ 
344 range. Because of fluorophilicity of the perfluorinated chains, full swelling of the triblock 345 polymers in chloroform is limited by a probable folding or formation of micellar domains. 346 Indeed, the triblock polymers appeared more difficult and longer to solubilize than non347 fluorinated PEG-PLA in common organic solvents such as chloroform, methylene chloride 348 and acetone. To confirm this different behavior, DLS analysis of fluorinated polymers at 25 $349 \mathrm{mg} / \mathrm{mL}$ in methylene chloride and chloroform was performed. It revealed an important 350 increase of scattered intensity compared to plain PEG-PLA (around $15000 \mathrm{kcps}$ for the 351 triblocks compared to $200 \mathrm{kcps}$ for PEG-PLA, see supplementary material Figure S4). This 352 indicates presence of aggregates such as micelles which confirms that the fluorinated block 353 strongly impacts the solubility and conformation of the polymers chains. 
355 Table 1. Degree of polymerization (DP), number-average molar mass $\left(M_{n}\right)$, dispersity $(\Theta)$ and glass transition temperature $\left(T_{g}\right)$ of PEG-PLA-PFMA polymers and their precursors.

\begin{tabular}{|c|c|c|c|c|c|c|}
\hline Polymer & 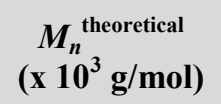 & $\begin{array}{c}\text { DP } \\
\text { PLA:PFMA }\end{array}$ & $\begin{array}{c}M_{n}^{\mathrm{NMR}} \\
\left.\text { (x } 10^{3} \mathrm{~g} / \mathrm{mol}\right)\end{array}$ & $\begin{array}{c}M_{n}{ }^{\mathrm{SEC}} \\
\left(\times 10^{3} \mathrm{~g} / \mathrm{mol}\right)\end{array}$ & $\boldsymbol{D}$ & $T_{\mathrm{g}}\left({ }^{\circ} \mathbf{C}\right)$ \\
\hline PEG-PLA & 25.0 & 257 & 23.5 & 24.3 & 1.29 & $13 \pm 1$ \\
\hline PEG-PLA-Br & 25.0 & 260 & 23.7 & 25.2 & 1.28 & ND \\
\hline PEG-PLA-PFMA $_{5}$ & 27.7 & $272: 4$ & 26.7 & 25.0 & 1.38 & $16 \pm 1$ \\
\hline PEG-PLA-PFMA $_{10}$ & 30.3 & $291: 7$ & 29.7 & 24.9 & 1.39 & $20 \pm 2$ \\
\hline PEG-PLA-PFMA 20 & 35.6 & $277: 15$ & 32.9 & 26.2 & 1.29 & $18 \pm 1$ \\
\hline
\end{tabular}

360 DSC thermograms of all polymers exhibited a single glass transition temperature $\left(T_{\mathrm{g}}\right)$ in the $361 \quad 16-20^{\circ} \mathrm{C}$ range for triblock copolymers, slightly higher than plain PEG-PLA $\left(T_{\mathrm{g}}=13^{\circ} \mathrm{C}\right)$ 362 (Table 1). The $T_{\mathrm{g}}$ of the PEG block is too low to be detected, and the $T_{\mathrm{g}}$ of both PLA and 363 PFMA blocks are probably very close to each other to be detected separately. Indeed, Li et al. 364 reported the synthesis of PEG-PFMA block copolymers and found a $T_{\mathrm{g}}$ of -24.3 or $-41.7^{\circ} \mathrm{C}$ 365 for the PEG block, and $19.5^{\circ} \mathrm{C}$ for the PFMA block, ${ }^{28}$ in agreement with our observations. 366 Moreover, the glass transition of PEG-PLA-PFMA 20 appears less sharp than the others 367 (supplementary material Figure S5), suggesting a stronger entanglement of polymer chains 368 induced by a higher proportion of perfluoroalkyl units. This is consistent with the study of Li 369 et al. where the glass transition of PFMA was observed only with the shorter PFMA block (28 370 fluorinated units) and not with increasing number of fluorinated units (36 and 38). ${ }^{28}$

371 A series of triblock copolymers containing a fluorinated block with a comb-like structure was 372 therefore successfully synthesized using a combination of ROP and ATRP. This will allow 373 studying the influence of the number of perfluoroalkyl pendant chains on polymers interfacial 374 properties and on nanocapsules characteristics. 
376 The importance of polymer interfacial behavior during the formulation process of 377 perfluorocarbon micro- and nanocapsules was highlighted in previous reports. ${ }^{18,35,36}$ In 378 particular, reducing the amount of PEG-PLGA in the formulation of PFOB nanocapsules led 379 to local dewetting and expulsion of some PFOB droplets stabilized by sodium cholate. ${ }^{18}$ The 380 interfacial tension at the PFOB/organic phase interface was therefore measured with each 381 triblock polymer (Figure 4). A reduction from 2.0 to $0.9-1.0 \mathrm{mN} / \mathrm{m}$ is observed upon addition 382 of each PEG-PLA-PFMA ${ }_{x}$ polymer at $25 \mathrm{mg} / \mathrm{mL}$ in methylene chloride, regardless of the 383 number of fluorinated units, whereas no decrease is induced by addition of plain PEG-PLA $(\gamma$ $384=2.0 \pm 0.3 \mathrm{mN} / \mathrm{m}$ ). The profile as a function of time after the drop formation is also different 385 between fluorinated polymers and the non-fluorinated one, showing a decrease of interfacial 386 tension during the first few seconds with fluorinated polymers only (Figure 4). These results 387 confirm that perfluoroalkyl pendant chains interact with PFOB and adsorb at the interface. 388 Such finding is consistent with the reported fluorophilic character of perfluorinated chains, 389 which usually form fluorous domains. ${ }^{37-39}$ In a previous study, no reduction of interfacial 390 tension could be observed with PLAs terminated by a linear fluorinated chain of length 391 ranging from $\mathrm{C}_{3} \mathrm{~F}_{7}$ to $\mathrm{C}_{13} \mathrm{~F}_{27}{ }^{19}$ Adsorption of PEG-PLA-PFMA $\mathrm{A}_{\mathrm{x}}$ polymers could potentially 392 be favored by their higher fluorine content as compared to PLA- $\mathrm{C}_{\mathrm{x}} \mathrm{F}_{2 \mathrm{x}+1}$ polymers. However, 393 the difference between PLA- $\mathrm{C}_{13} \mathrm{~F}_{27}$ and PEG-PLA-PFMA 5 is not so important as compared to 394 differences between all triblock polymers when taking into account the real degrees of 395 polymerization: $25 \mathrm{mg}$ of polymer contains $\sim 45 \mu \mathrm{mol}$ of fluorine for PLA-C $\mathrm{C}_{13} \mathrm{~F}_{27}$ and $\sim 64$ $396 \mu$ mol for PEG-PLA-PFMA 5 . This quantity then reaches $\sim 100 \mu$ mol for PEG-PLA-PFMA 10 397 and $\sim 194 \mu \mathrm{mol}$ PEG-PLA-PFMA 20 . Adsorption of triblock polymers is therefore probably 398 favored by their comb-like architecture. In linear fluorinated PLAs, the fluorinated chain 399 might be hidden by the PLA chain, whereas with the methacrylate backbone, the fluorinated 
400 part is more rigid and more voluminous, making it more exposed and able to adsorb at the

401 PFOB-solvent interface.

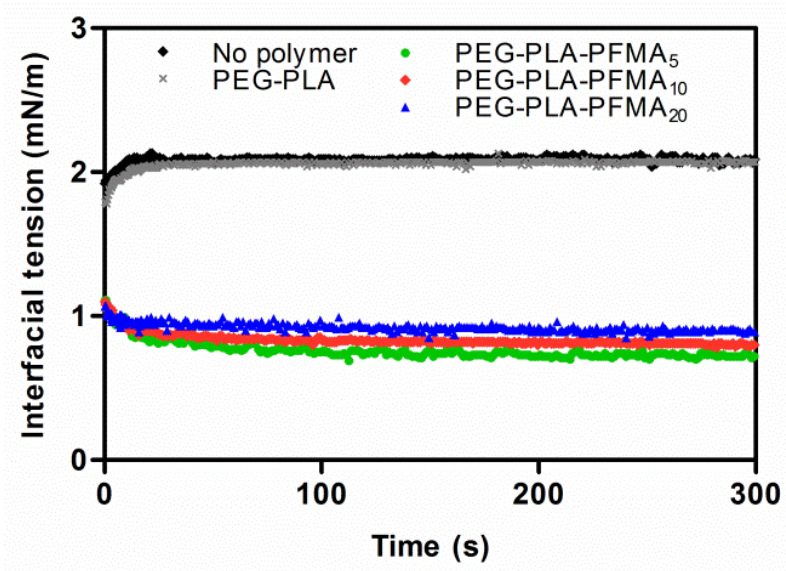

\begin{tabular}{lc}
\hline \multicolumn{1}{c}{ Polymer } & $\begin{array}{c}\text { Interfacial tension } \\
(\mathbf{m N} / \mathbf{m})\end{array}$ \\
\hline No polymer & $2.0 \pm 0.3$ \\
PEG-PLA & $2.0 \pm 0.3$ \\
PEG-PLA-PFMA $_{5}$ & $0.9 \pm 0.1$ \\
PEG-PLA-PFMA $_{10}$ & $0.9 \pm 0.1$ \\
PEG-PLA-PFMA $_{20}$ & $1.0 \pm 0.1$ \\
\hline
\end{tabular}

403

404

405

406

407

408

409

410

Figure 4. Interfacial tension measurements at the interface between PFOB and methylene chloride solutions of each polymer at $25 \mathrm{mg} / \mathrm{mL}$ with the pendant drop method: typical profiles as a function of time after the drop formation (top) and interfacial tension values at $200 \mathrm{~s}$ presented as mean $\pm \mathrm{SD}(\mathrm{n}>6)$ (bottom).

\subsection{PFOB nanocapsules: physical characterization}

PFOB nanocapsules (NCs) were formulated using an emulsion evaporation process. ${ }^{16,17}$ Since the objective was to reduce shell thickness, the initial amount of polymer in the organic phase was decreased (50, 30 and $20 \mathrm{mg})$, while keeping the amount of PFOB constant.

\section{Size distribution and zeta potential}

For a fixed polymer quantity, NCs mean hydrodynamic diameters are slightly larger with all PEG-PLA-PFMA $_{x}(117-147 \mathrm{~nm})$ compared to PEG-PLA $(113-131 \mathrm{~nm})($ Table 2). As observed with interfacial tension results, the number of fluorinated pendants does not seem to 
415 have an influence on size and zeta potential. The polymer mass in the formulation is a more

416 important parameter. Indeed, NCs formulated from $20 \mathrm{mg}$ of polymer exhibit larger sizes than

417 NCs from 50 and $30 \mathrm{mg}$, especially with the fluorinated polymers $(136-147 \mathrm{~nm}$ at $20 \mathrm{mg}$

418 compared to $117-119 \mathrm{~nm}$ at higher polymer amounts). For all polymers, the polydispersity

419 (PDI) increases as the polymer quantity decreases $(<0.19$ at $50 \mathrm{mg},>0.28$ at $20 \mathrm{mg}$ ),

420 suggesting a wider size distribution at low polymer amount. This might arise from the

421 presence of a second population of objects, such as non-encapsulated PFOB droplets, despite

422 the addition of perfluorinated chains in the polymer, as previously observed with PLGA-

423 PEG. ${ }^{18}$ For all polymers, the zeta potential is negative and no significant difference is induced

424 by the number of perfluoroalkyl chains (Table 2).

425 Table 2. Characterization of nanocapsules prepared from 50, 30 or $20 \mathrm{mg}$ of each polymer.

Data are presented as mean $\pm \mathrm{SD}(\mathrm{n}>3)$ for $\mathrm{d}_{\mathrm{H}}$ and $\zeta$ values.

\begin{tabular}{|c|c|c|c|c|c|c|c|c|c|}
\hline \multirow[b]{2}{*}{ Polymer } & \multicolumn{3}{|c|}{$50 \mathrm{mg}$} & \multicolumn{3}{|c|}{$30 \mathrm{mg}$} & \multicolumn{3}{|c|}{$20 \mathrm{mg}$} \\
\hline & $d_{\mathrm{H}}(\mathrm{nm})$ & PDI & $\zeta(\mathrm{mV})$ & $d_{\mathrm{H}}(\mathrm{nm})$ & PDI & $\zeta(\mathrm{mV})$ & $d_{\mathrm{H}}(\mathrm{nm})$ & PDI & $\zeta(\mathbf{m V})$ \\
\hline PEG-PLA & $113 \pm 3$ & 0.19 & $-17 \pm 10$ & $113 \pm 3$ & 0.22 & $-23 \pm 9$ & $131 \pm 8$ & 0.28 & $-29 \pm 7$ \\
\hline PEG-PLA-PFMA 5 & $117 \pm 2$ & 0.17 & $-15 \pm 8$ & $120 \pm 5$ & 0.24 & $-20 \pm 4$ & $140 \pm 9$ & 0.34 & $-30 \pm 15$ \\
\hline PEG-PLA-PFMA 10 & $116 \pm 5$ & 0.17 & $-15 \pm 7$ & $120 \pm 6$ & 0.26 & $-20 \pm 5$ & $136 \pm 12$ & 0.35 & $-21 \pm 6$ \\
\hline PEG-PLA-PFMA $_{20}$ & $119 \pm 3$ & 0.16 & $-15 \pm 9$ & $123 \pm 2$ & 0.26 & $-21 \pm 5$ & $147 \pm 3$ & 0.44 & $-23 \pm 10$ \\
\hline
\end{tabular}

427

429 PFOB encapsulation efficiency in NCs was measured by ${ }^{19} \mathrm{~F}$ NMR after freeze-drying to 430 remove any non-encapsulated PFOB droplets remaining. As shown in Figure 5, more PFOB

431 is encapsulated in PEG-PLA-PFMA $\mathrm{A}_{\mathrm{x}}$ NCs compared to plain PEG-PLA NCs. When 432 comparing to the PLA-PEG control, the encapsulation efficacy of PFOB is significantly 433 higher for PEG-PLA-PFMA 5 and PEG-PLA-PFMA 10 ers for all initial masses of polymer but 434 not for PEG-PLA-PFMA 20 . The difference appears more important at low polymer amounts, 
with 49-61\% PFOB encapsulated in PEG-PLA-PFMA 5 and PEG-PLA-PFMA 10 NCs 436 compared to $35 \%$ in PEG-PLA NCs at $30 \mathrm{mg}$, and $37-47 \%$ compared to $24 \%$ at $20 \mathrm{mg}$. Such results are consistent with interfacial tension measurements and demonstrate that fluorophilic

438 interactions between PFOB and the perfluorinated units of the polymers allow entrapping 439 more PFOB into the NCs. One can also observe that PFOB encapsulation efficiency is slightly 440 lower with PEG-PLA-PFMA 20 compared to PEG-PLA-PFMA 5 and PEG-PLA-PFMA 10 441 (about $9-12 \%$ of difference). This could be due to a stronger self-association of the polymer 442 with the largest fluorinated block of 20 pendants, reducing their ability to interact with PFOB 443 as compared with shorter blocks of $5-10$ fluorinated units.

444

445 446 447 448 449

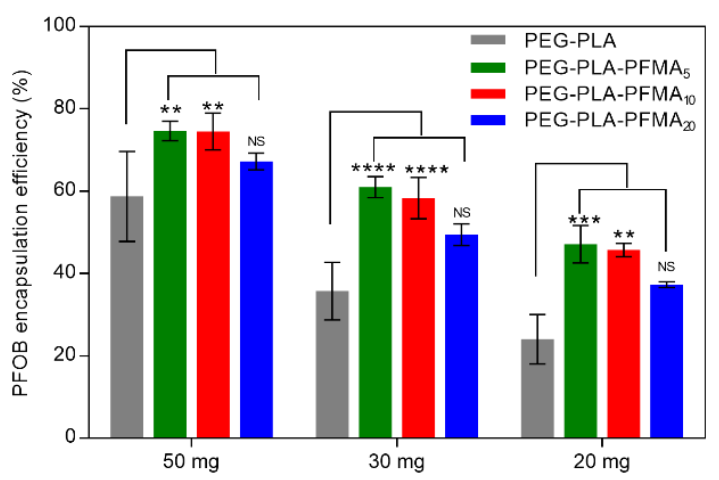

Figure 5. PFOB encapsulation efficiency in freeze-dried NCs. Results are presented as mean $\pm \mathrm{SD}(\mathrm{n}=4)$. Statistical significance was analyzed using an ANOVA test: $* * * * \mathrm{p}<0.0001$,

$$
* * * \mathrm{p}<0.001, * * \mathrm{p}<0.01
$$

\section{Nanocapsules morphology}

Nanocapsules were then imaged by TEM with negative staining and cryo-TEM. In TEM images, one can observe mostly spherical objects with PEG-PLA (Figure 6A,B,C) whereas PEG-PLA-PFMA $_{x}$ NCs exhibit more heterogeneous morphologies (Figure 6 and supplementary material S6 to S9). Indeed, capsules appear less spherical and a lot of broken capsules can be observed at low polymer amounts (Figure 6E,F,H,I,K,L). These broken 
456 mg of PEG-PLA-PFMA , are sometimes very large (up to $1 \mu \mathrm{m}$ diameter, see supplementary 457 material). Such finding is surprising since NCs are filtered on $0.45 \mu \mathrm{m}$ after the emulsion 458 evaporation process. These objects might be very deformable to pass through the filter, and 459 might be broken because of the filtration or because they are under vacuum during TEM 460 observation. These large capsules can therefore explain the high PDI values observed at low 461 fluorinated polymer amounts (Table 2).
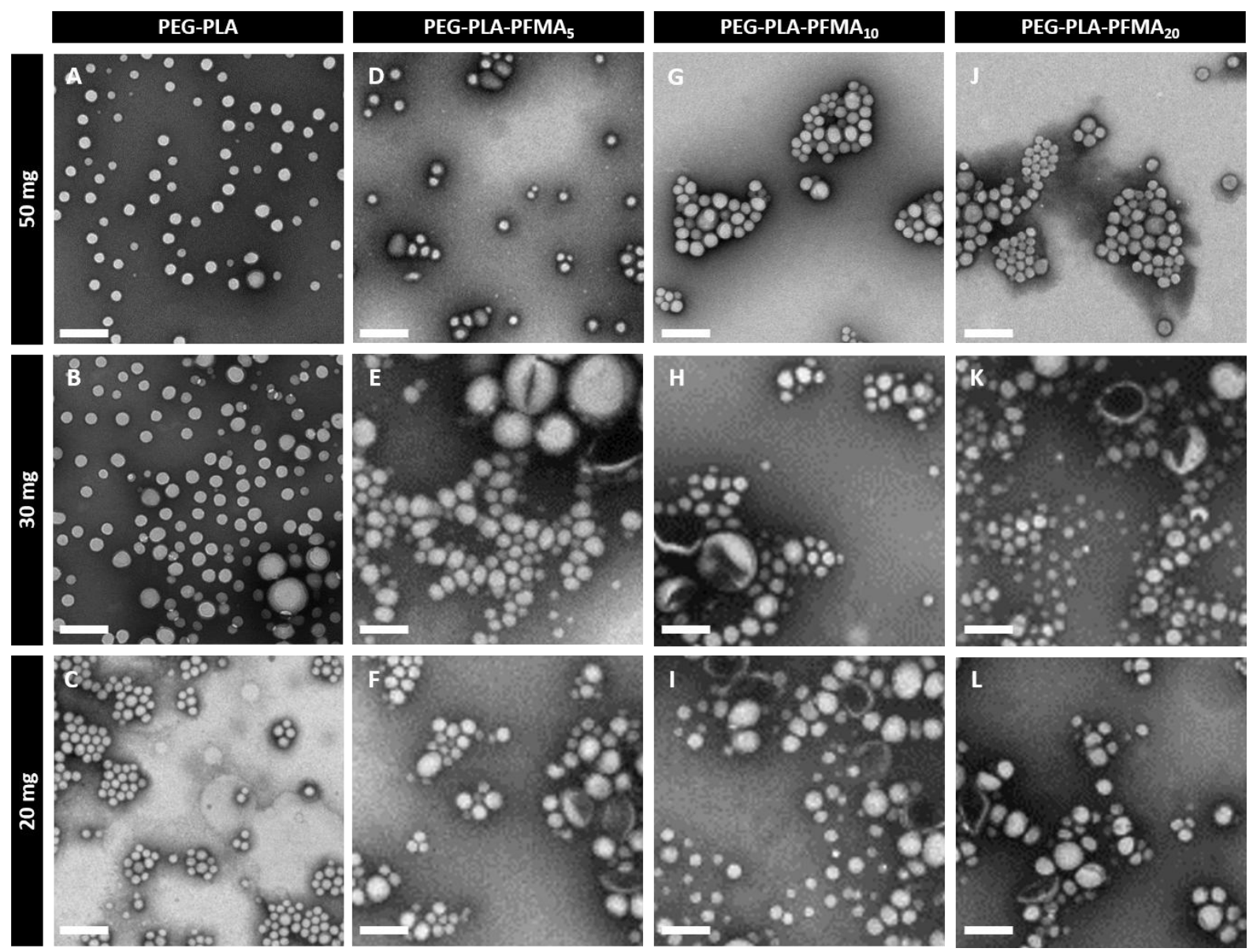

463

Figure 6. TEM images of formulated NCs with negative staining (scale bars $=200 \mathrm{~nm}$ ). Additional images are shown in supplementary material.

465 Cryo-TEM images allow distinguishing the dark PFOB core, with high electronic density, 466 from the lighter polymeric shell (Figure 7 and supplementary material S6 to S9). NCs also 467 present a white meniscus in the core, due to rapid freezing, which causes solidification and 
shrinking of PFOB. PFOB therefore does not fill entirely the shell cavity anymore as observed

469 previously. ${ }^{18,19,40}$ One can observe that NCs morphology is strongly influenced by the number

470 of fluorinated chains and the amount of polymer used for formulation. Indeed, all PEG-PLA

471 NCs possess a spherical core-shell structure (Figure 7A,B,C), whereas the presence of five

472 perfluoroalkyl chains induces the formation of some elongated NCs with a non-centered 473 PFOB core looking like sunny-side up eggs (shown by red stars in Figure 7D,E). Such 474 elongated morphology had already been observed with COOH-PEG-PLA NCs. This was 475 attributed to an interfacial instability due to electrostatic repulsions between deprotonated 476 carboxy functions leading to an increase of the total surface area. ${ }^{30}$ Comparatively, with PEG477 PLA-PFMA 5 , we can imagine that the incompatibility between the various blocks may force 478 the chains to adopt a particular conformation leading to an increase of the total surface area. 479 The same type of morphologies (shown by red stars) is observed with 50 and $30 \mathrm{mg}$ of PEG480 PLA-PFMA 10 , but with additional dark domains (shown by red arrows) in the same object 481 (Figure 7G,H), which correspond either to other PFOB cores, or to fluorinated rich domains 482 formed by aggregation of the perfluoroalkyl chains of the polymer. ${ }^{41}$ PEG-PLA-PFMA 20 483 leads to NCs with 2 or 3 distinct PFOB cores at high polymer amounts, as shown by blue 484 circles in Figure 7J,K. Such multi-core structures are probably favored by strong interactions 485 between PFOB and perfluoroalkyl pendants. However, at $20 \mathrm{mg}$ of each fluorinated polymer, 486 although morphologies are still a bit heterogeneous within a same sample, one can observe a 487 majority of capsules with a single centered PFOB core and a thin shell (Figure 7F,I,L). 488 Interestingly, some are not perfectly spherical and seem ellipsoidal/elongated (shown by 489 yellow triangles), which may indicate different mechanical properties. In this type of capsules, 490 the PFOB core is not spherical and the shell thickness is homogeneous within the whole 491 capsule, which is different from the other elongated NCs observed at higher polymer amounts. 

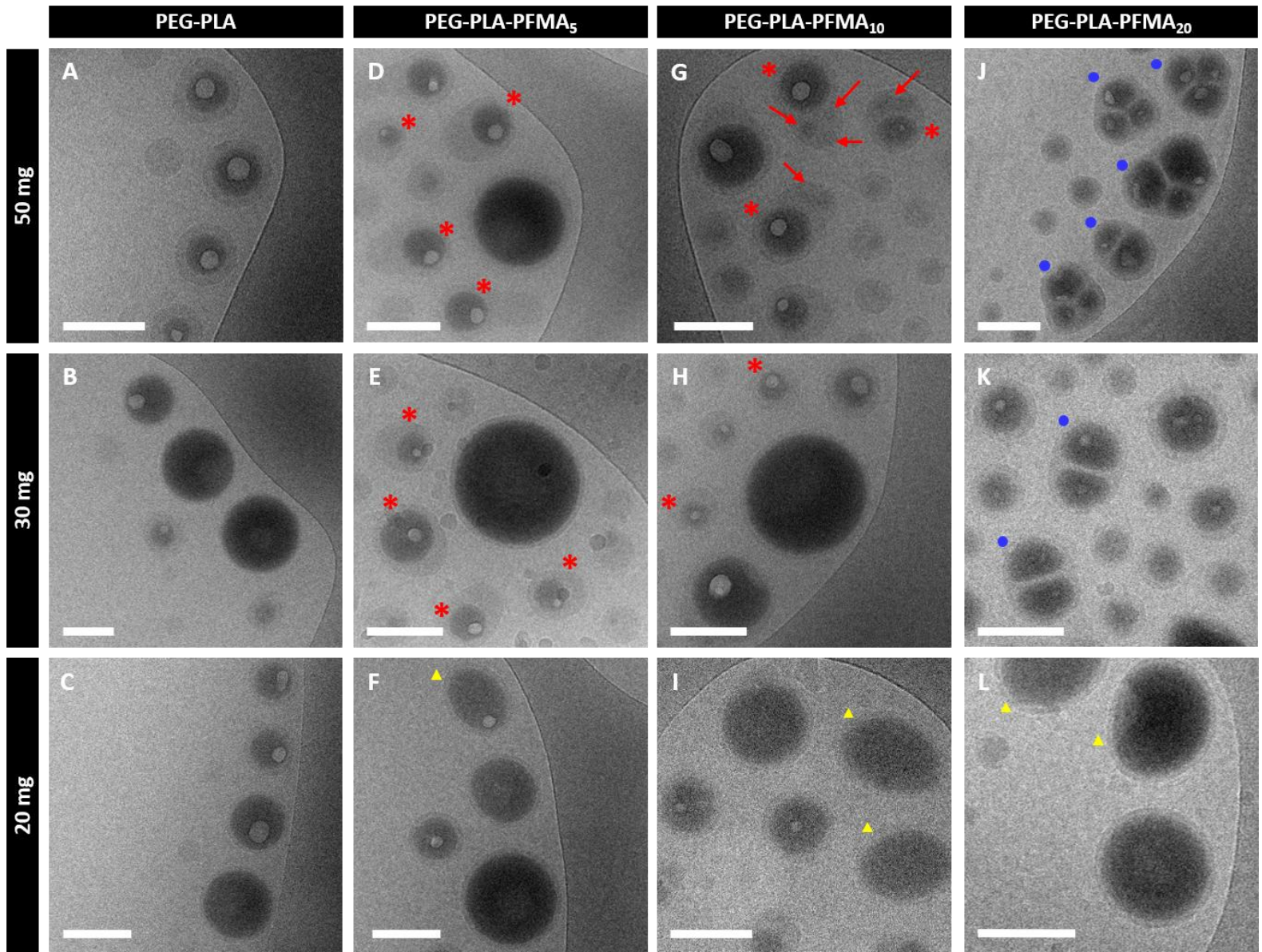

Figure 7. Cryo-TEM images of formulated NCs (scale bars $=100 \mathrm{~nm}$ ). Additional images are

494 given in supplementary material. Red stars show elongated NCs with a non-centered spherical

495 PFOB core at high amounts of PEG-PLA-PFMA 5 and PEG-PLA-PFMA 10 . In the case of

496 PEG-PLA-PFMA 10 , this type of elongated NCs also possesses additional darker domains

497 shown by red arrows. Blue circles show NCs with 2 or 3 distinct PFOB cores. Yellow

498 triangles show ellipsoidal NCs with a single non-spherical PFOB core and a shell thickness homogeneous within the same capsule.

Shell thickness

501 Small Angle Neutron Scattering (SANS) was used to statistically determine shell thickness.

502 We focused on PEG-PLA-PFMA 5 and PEG-PLA-PFMA 10 which showed better PFOB

503 encapsulation efficiency and higher solubility in methylene chloride than PEG-PLA-PFMA 20.

504 NCs were resuspended in the appropriate mixture of $\mathrm{H}_{2} \mathrm{O}$ and $\mathrm{D}_{2} \mathrm{O}$ to match the scattering 
length density of the PFOB core and allow focusing on the polymeric shell. Scattered

506 intensity curves were fitted with the vesicle model, assuming a log-normal distribution for 507 both shell thickness and core radius. One example of a satisfying fit and the best fit 508 parameters obtained for shell thickness are represented in Figure 8. Fitted curves and 509 numerical values of shell thickness and core radius are given in supplementary material 510 (Figure S10 and Table S1). Mean PFOB core radii are all in the same range $(53-56 \mathrm{~nm})$ with 511 a high polydispersity, in agreement with DLS measurements. The mean thickness of PEG512 PLA NCs is not impacted by the amount of polymer, with values between 16 and $14.5 \mathrm{~nm}$. 513 However, with fluorinated triblock polymers, the mean thickness is decreasing down to 13.5 $514 \mathrm{~nm}$ and $11 \mathrm{~nm}$ for $20 \mathrm{mg}$ of PEG-PLA-PFMA 5 and PEG-PLA-PFMA 10 , respectively, as 515 compared with 50 and $30 \mathrm{mg}$ polymer where no difference can be observed. This decrease is 516 meaningful as the precision of SANS fitting is on the 1-2 $\mathrm{nm}$ order. A high polydispersity is 517 nevertheless observed for all samples, especially for NCs made from higher fluorinated 518 polymer amounts. This can be attributed to PFOB cores not being always well centered as 519 seen on cryo-TEM images.
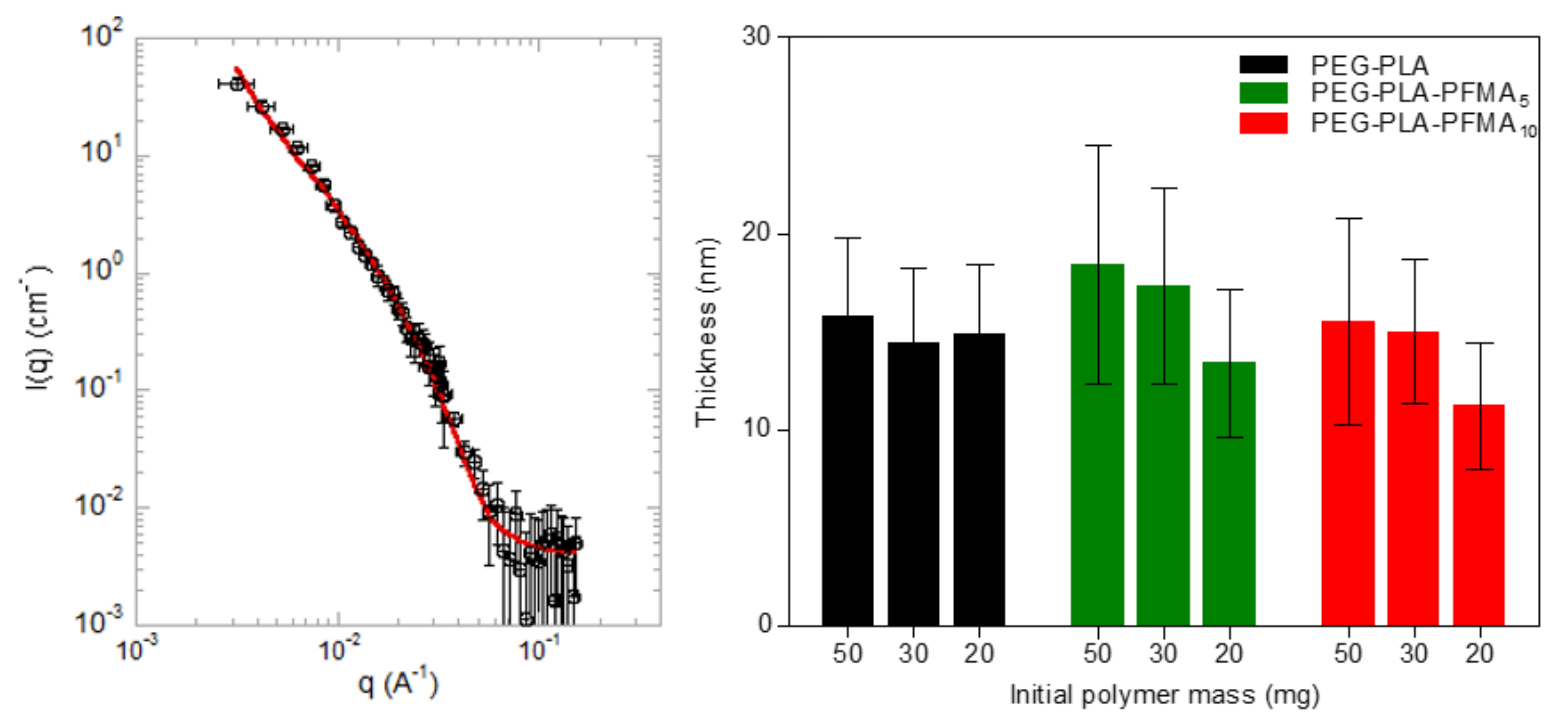

521 Figure 8. Experimental scattered intensity curve (black circles) of NCs made from $20 \mathrm{mg}$ 522 PEG-PLA-PFMA 10 in PFOB matching condition fitted with the vesicle model (red line) (left) 

and shell thickness values of NCs determined by fitting with the vesicle model (mean \pm SD) (right).

\subsection{Cytotoxicity studies}

The biological inertness of perfluorocarbons is well documented. ${ }^{42}$ Nevertheless, perfluoroalkyl moieties are often associated to a certain toxicity due to their low excretion profiles and prolonged retention in the organism, especially linear perfluorinated chains longer than eight carbons. ${ }^{43-45}$ Therefore the potential cytotoxicity of PEG-PLA-PFMA NCs was investigated using an MTT assay on two representative cell types. Human umbilical vein endothelial cells (HUVEC) were chosen for their high sensitivity and rapid response to external stimuli which make them a widely used in vitro model for polymer cytotoxicity evaluation. ${ }^{46}$ J774.A1 cells play a key role in phagocytosis and were chosen to highlight the possible toxicity of NCs after being engulfed by macrophages. At both 24 and $72 \mathrm{~h}$ incubation times, cell viability of HUVEC slightly decreases as NCs concentration increases, but remains above $70 \%$ until $1 \mathrm{mg} / \mathrm{mL}$, and above $50 \%$ at $10 \mathrm{mg} / \mathrm{mL}$, with no difference between the polymers (Figure 9A and Figure S11A). Regarding J774.A1, cellular viability remains above $80 \%$ until $1 \mathrm{mg} / \mathrm{mL}$ at both incubation times. A strong viability decrease down to $45 \%$ after $24 \mathrm{~h}$ and $20 \%$ after $72 \mathrm{~h}$ is observed at $10 \mathrm{mg} / \mathrm{mL}$, but this high concentration is unlikely to be reached in vivo (Figure 9A and Figure S11A). For both cell types and both incubation times, the perfluoroalkyl chains do not induce any specific toxicity in comparison to plain PEGPLA, with no influence of the number of perfluoroalkyl chains. These results concur with reports from Koda et al. on the low toxicity of an amphiphilic fluorous random copolymer containing PEG and $\mathrm{C}_{8} \mathrm{~F}_{17}$ pendants. ${ }^{34}$ 
A
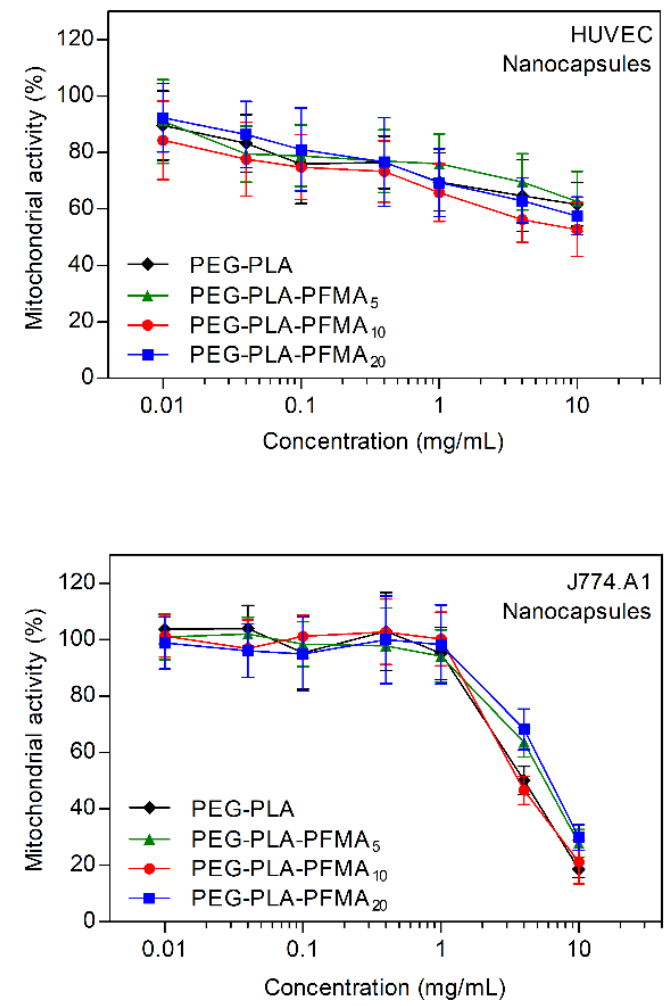

B
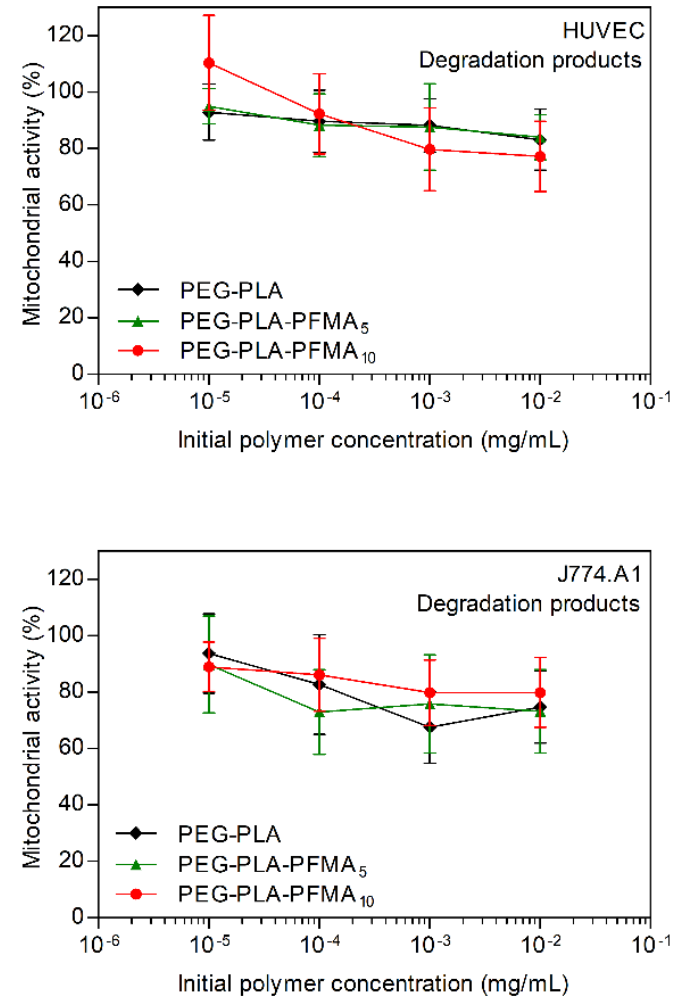

547 incubation with nanocapsules (A) or polymers degradation products (B). Results are presented as mean $\pm \mathrm{SD}(\mathrm{n}=3)$.

549 PEG-PLA diblock copolymer is well known to be degradable into non-toxic products (lactic 550 acid and polyethylene glycol). However, toxicity of the remaining short PFMA block after 551 degradation of the triblock copolymers must be investigated. Accelerated hydrolytic 552 degradations of PEG-PLA-PFMA 5 , PEG-PLA-PFMA 10 , and PEG-PLA as control, were 553 carried out in basic conditions. The in vitro cytotoxicity of degradation products was then 554 evaluated using an MTT assay on the same cell lines as for NCs. Due to insolubility issues, 555 only low concentrations could be tested (maximum $0.01 \mathrm{mg} / \mathrm{mL}$ of initial polymer). In this 556 range of concentrations, high HUVEC cellular viabilities $(>70 \%)$ were observed at both 557 incubation times (Figure 9B and Figure S11B). J774.A1 cells show a slightly higher 558 sensitivity depending on the incubation time, with cell viabilities above $87 \%$ after $24 \mathrm{~h}$ and 
above $67 \%$ after $72 \mathrm{~h}$. Within experimental error, no significant differences between polymers can be observed for both cell types, indicating an absence of obvious toxicity arising from fluorinated degradation products (Figure 9B and Figure S11B). These results are encouraging and additional in vivo studies will be required to evaluate the potential toxicity arising from a prolonged exposure to the degradation products.

\subsection{In vitro ultrasound measurements}

Finally, the acoustic response of NCs made from 30 and $20 \mathrm{mg}$ polymer was evaluated in vitro at $5 \mathrm{MHz}$. Figure $10 \mathrm{~A}$ presents the ultrasound scattered intensities measured at fundamental frequency and subtracted by the background level produced by Milli-Q water. No non-linear response could indeed be detected with our capsules, in agreement with previous studies showing the absence of nonlinear scattering with nano-sized agents. ${ }^{47,48}$ At $30 \mathrm{mg}$ polymer, all samples did not yield an ultrasound signal much higher than the background (intensity $<0.9 \times 10^{3}$ arbitrary units, a.u.). However, at $20 \mathrm{mg}$ polymer, the ultrasound scattered intensity increases with the number of fluorinated pendant chains, from $1.4 \times 10^{3}$ a.u. with plain PEG-PLA to $2.5 \times 10^{3}$ a.u. with PEG-PLA-PFMA 5 and $5.3 \times 10^{3}$ a.u. with PEG-PLA-PFMA 10 . Such enhancement probably arises from several contributions which are summarized in Table 3. As shown by De Jong et al., the scattering cross section of a particle is defined as $S C S=\frac{4 \pi}{9} k^{4} R^{6}\left[\left(\frac{\kappa_{d}-\kappa}{\kappa}\right)^{2}+\frac{3}{4} \frac{\left(\rho_{d}-\rho\right)^{2}}{\left(\rho_{d}+\rho\right)^{2}}\right]$ where $k$ is the wavenumber, $R$ is the radius of the particle, $\kappa_{d}$ and $\kappa$ the compressibilities of respectively the particle and the medium, $\rho_{d}$ and $\rho$ the densities of respectively the particle and the medium. ${ }^{49}$ A contrast agent will therefore backscatter ultrasound waves more effectively if its radius is larger and if its physical properties (compressibility and density) differ a lot from the ones of the surrounding medium. Here, the slight diameter difference (up to $27 \mathrm{~nm}$ ) could hardly be considered 
583

responsible for the higher efficacy in scattering ultrasound. One of the main contribution is

584 probably the reduction of shell thickness (down to $13.5 \mathrm{~nm}$ for PEG-PLA-PFMA 5 and $11 \mathrm{~nm}$

585 for PEG-PLA-PFMA 10 ) which may increase the capsules compressibility and echogenicity as

586 previously observed. ${ }^{15}$ Indeed, AFM indentation experiments performed on PFOB

587 microcapsules have shown that a thinner shell leads to overall softer capsules. ${ }^{50}$ Moreover,

588 higher encapsulated PFOB contents and higher amounts of fluorinated chains in the polymers

589 both increase capsule density and strengthen the difference of acoustic impedance with the

590 surrounding medium, as previously observed with linear fluorinated PLAs. ${ }^{19}$ Although the

591 quantity of PFOB and fluorinated chains is also high in samples made from $30 \mathrm{mg}$ of PEG-

592 PLA-PFMA 5 and PEG-PLA-PFMA 10 , these two samples possess a larger shell thickness $(>$

$59315 \mathrm{~nm}$ ) and a different morphology with a non-centered PFOB core (Figure 10B). The

594 observed differences in capsules morphology are probably related to some differences in their

595 mechanical properties which impact their response to ultrasound waves. AFM indentation

596 experiments should be performed in the future to relate mechanical properties and ultrasound

597 signal.

598 Nanocapsules made from $20 \mathrm{mg}$ of fluorinated triblock polymers therefore appear as

599 promising UCAs. Although the measured ultrasound scattered intensities were still lower that

600 with SonoVue ${ }^{\circledR}$ microbubbles $\left(16.5 \times 10^{3}\right.$ a.u.) due to their large radius (20-fold larger than

$601 \mathrm{NCs}$ ) and gaseous core, these NCs have greater potential to accumulate into the tumors by the

602 EPR effect and allow contrast ultrasound imaging of tumors. 


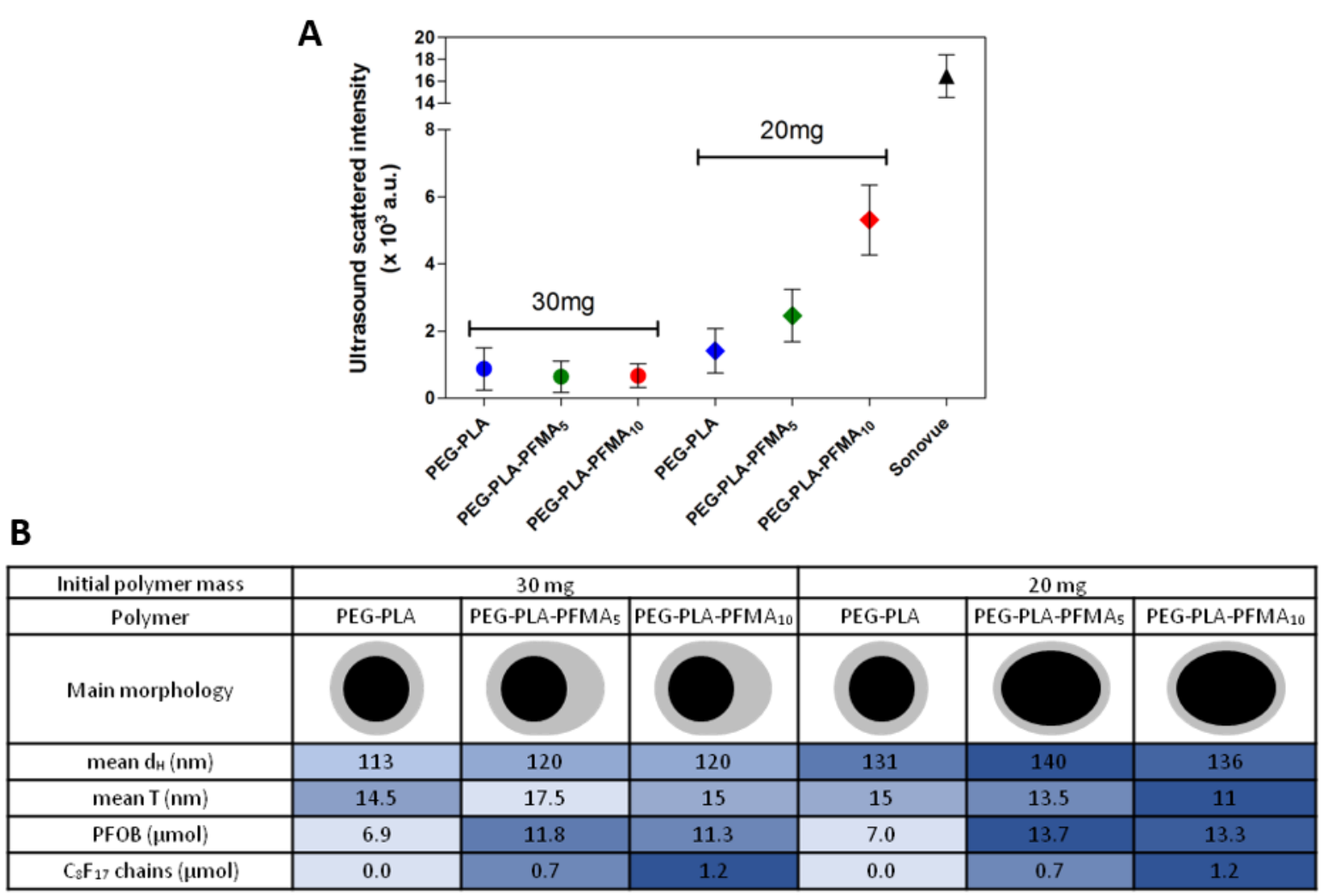

604 Figure 10. (A) Ultrasound scattered intensity by NCs resuspended at $5 \mathrm{mg} / \mathrm{mL}$ made from 30 $\mathrm{mg}$ (circles) and $20 \mathrm{mg}$ (diamonds) of each polymer and by Sonovue microbubbles (dark triangle) as positive control. Results are presented as mean \pm SEM ( $>$ 9). (B) Table summarizing NCs characteristics which could account for differences of ultrasound scattering: simplified representation of their morphology, mean hydrodynamic diameter $\left(\mathrm{d}_{\mathrm{H}}\right)$,

609 mean shell thickness (T), PFOB quantity and $\mathrm{C}_{8} \mathrm{~F}_{17}$ chains quantity contained in $1 \mathrm{~mL}$ of 610 formulation resuspended at a final polymer concentration of $5 \mathrm{mg} / \mathrm{mL}$ for ultrasound measurements. 
613 Triblock PEG-PLA-PFMA polymers with distinct lengths of PFMA block (5, 10 or 20

614 fluorinated pendant chains) were successfully synthesized and were shown to adsorb at the $615 \mathrm{PFOB} /$ methylene chloride interface. These favorable fluorous interactions led to an increase 616 of the PFOB encapsulation efficiency into nanocapsules made of fluorinated polymers 617 compared to plain PEG-PLA. The morphology of the nanocapsules was strongly influenced 618 by the number of perfluorinated chains and the amount of polymer used for formulation: 619 capsules with several PFOB cores or fluorinated-rich domains are obtained at high polymer 620 amount, while a single PFOB core and a thinner shell are observed at low polymer amount. 621 SANS measurements confirmed the observed reduction of mean shell thickness down to 11 622 nm with PEG-PLA-PFMA ${ }_{10}$, which led to a 3.7-fold higher in vitro ultrasound response at 5 $623 \mathrm{MHz}$ compared to plain PEG-PLA nanocapsules. Finally, no in vitro cytotoxicity was induced 624 by both the fluorinated polymers and their degradation products. Results are encouraging, and 625 future work will consist in performing in vivo studies to confirm the potential of these 626 PEGylated/fluorinated nanocapsules to be used as ultrasound contrast agents for tumor 627 imaging.

\section{Supporting information}

629 Supporting information is available: scheme of the experimental set up for in vitro ultrasound 630 measurements, ${ }^{1} \mathrm{H}$ NMR spectra of PEG-PLA and PEG-PLA-Br, SEC chromatograms, DLS 631 of polymers in methylene chloride and chloroform, DSC thermograms, additional TEM and 632 cryo-TEM images, SANS curves fitting, cytotoxicity results after $24 \mathrm{~h}$ incubation, DLS curves 633 of NCs (correlation and distribution functions). 
636 Authors would like to thank Mehrez Sghaier and Najet Yagoubi from Laboratoire Matériaux 637 et Santé (EA401, Univ. Paris-Sud) for DSC experiments, Flora Lefebvre for some NMR 638 measurements and Stéphanie Denis (Institut Galien Paris-Sud) for her help with cell culture. 639 This work has been supported by the Région Ile-de-France in the framework of DIM Nano-K. 640 The present work has benefited also from the core facilities of Imagerie- Gif, 641 (http://www.i2bc.paris- saclay.fr), member of IBiSA (http://www.ibisa.net), supported by 642 "France- BioImaging" (ANR- 10- INBS- 04- 01), and the Labex "Saclay Plant Science" 643 (ANR- 11- IDEX- 0003- 02). SANS analysis was performed using SasView software, 644 originally developed by the DANSE project under NSF award DMR-0520547. Authors 645 acknowledge financial support from ANR (Investissements d'Avenir, Nanobiotechnologies, 646 ANR-10-NANO-06-04). Institut Galien Paris-Sud is a member of the Laboratory of 647 Excellence LERMIT supported by a grant from ANR (ANR-10-LABX-33). 
650 (1) Boissenot, T.; Bordat, A.; Fattal, E.; Tsapis, N. Ultrasound-Triggered Drug Delivery for Cancer 651 Treatment Using Drug Delivery Systems: From Theoretical Considerations to Practical 652 Applications. Journal of Controlled Release. 2016, pp 144-163.

653 (2) Schutt, E. G.; Klein, D. H.; Mattrey, R. M.; Riess, J. G. Injectable Microbubbles as Contrast Agents for Diagnostic Ultrasound Imaging: The Key Role of Perfluorochemicals. Angew. Chemie-International Ed. 2003, 42 (28), 3218-3235.

656

(3) Paefgen, V.; Doleschel, D.; Kiessling, F. Evolution of Contrast Agents for Ultrasound Imaging and Ultrasound-Mediated Drug Delivery. Front. Pharmacol. 2015, 6.

658 (4) Schneider, M.; Arditi, M.; Barrau, M. B.; Brochot, J.; Broillet, A.; Ventrone, R.; Yan, F. Br1 - a New Ultrasonographic Contrast Agent Based on Sulfur Hexafluoride-Filled Microbubbles. Invest. Radiol. 1995, $30(8), 451-457$.

(5) Fisher, N. G.; Christiansen, J. P.; Leong-Poi, H.; Jayaweera, A. R.; Lindner, J. R.; Kaul, S. Myocardial and Microcirculatory Kinetics of BR14, a Novel Third-Generation Intravenous Ultrasound Contrast Agent. J. Am. Coll. Cardiol. 2002, 39 (3), 530-537.

(6) Lindner, J. R. Microbubbles in Medical Imaging: Current Applications and Future Directions. Nat. Rev. Drug Discov. 2004, 3 (6), 527-532.

666 (7) Abou-Saleh, R. H.; Peyman, S. A.; Johnson, B. R. G.; Marston, G.; Ingram, N.; Bushby, R.; Coletta, P. L.; Markham, A. F.; Evans, S. D. The Influence of Intercalating Perfluorohexane into Lipid Shells on Nano and Microbubble Stability. Soft Matter 2016, 12 (34), 7223-7230.

(8) Yuan, F.; Dellian, M.; Fukumura, D.; Leunig, M.; Berk, D. A.; Torchilin, V. P.; Jain, R. K. VascularPermeability in a Human Tumor Xenograft - Molecular-Size Dependence and Cutoff Size. Cancer Res. 1995, 55 (17), 3752-3756. 
674 (10) Cosco, D.; Fattal, E.; Fresta, M.; Tsapis, N. Perfluorocarbon-Loaded Micro and Nanosystems for Medical Imaging: A State of the Art. J. Fluor. Chem. 2015, 171, 18-26.

676

(11) El-Sherif, D. M.; Wheatley, M. A. Development of a Novel Method for Synthesis of a Polymeric Ultrasound Contrast Agent. J. Biomed. Mater. Res. A 2003, 66 (2), 347-355.

(12) Chlon, C.; Guedon, C.; Verhaagen, B.; Shi, W. T.; Hall, C. S.; Lub, J.; Bohmer, M. R. Effect of Molecular Weight, Crystallinity, and Hydrophobicity on the Acoustic Activation of Polymer-Shelled Ultrasound Contrast Agents. Biomacromolecules 2009, 10 (5), 1025-1031.

(13) Yang, P.; Li, D.; Jin, S.; Ding, J.; Guo, J.; Shi, W. B.; Wang, C. C. Stimuli-Responsive Biodegradable Poly(Methacrylic Acid) Based Nanocapsules for Ultrasound Traced and Triggered Drug Delivery System. Biomaterials 2014, 35 (6), 2079-2088.

(14) Sanna, V.; Pintus, G.; Bandiera, P.; Anedda, R.; Punzoni, S.; Sanna, B.; Migaleddu, V.; Uzzau, S.; Sechi, M. Development of Polymeric Microbubbles Targeted to Prostate-Specific Membrane Antigen as Prototype of Novel Ultrasound Contrast Agents. Mol. Pharm. 2011, 8 (3), 748-757.

(15) Pisani, E.; Tsapis, N.; Galaz, B.; Santin, M.; Berti, R.; Taulier, N.; Kurtisovski, E.; Lucidarme, O.; Ourevitch, M.; Doan, B. T.; et al. Perfluorooctyl Bromide Polymeric Capsules as Dual Contrast Agents for Ultrasonography and Magnetic Resonance Imaging. Adv. Funct. Mater. 2008, 18 (19), $2963-2971$.

(16) Diou, O.; Tsapis, N.; Giraudeau, C.; Valette, J.; Gueutin, C.; Bourasset, F.; Zanna, S.; Vauthier, C.; Fattal, E. Long-Circulating Perfluorooctyl Bromide Nanocapsules for Tumor Imaging by (FMRI)-F19. Biomaterials 2012, 33 (22), 5593-5602.

(17) Pisani, E.; Tsapis, N.; Paris, J.; Nicolas, V.; Cattel, L.; Fattal, E. Polymeric Nano/Microcapsules of Liquid Perfluorocarbons for Ultrasonic Imaging: Physical Characterization. Langmuir 2006, 22 (9), 4397-4402.

(18) Diou, O.; Brulet, A.; Pehau-Arnaudet, G.; Morvan, E.; Berti, R.; Astafyeva, K.; Taulier, N.; Fattal, E.; Tsapis, N. PEGylated Nanocapsules of Perfluorooctyl Bromide: Mechanism of Formation, Influence of Polymer Concentration on Morphology and Mechanical Properties. Colloids Surf B Biointerfaces 
(19) Houvenagel, S.; Picheth, G.; Dejean, C.; Brulet, A.; Chenneviere, A.; Couture, O.; Huang, N.; Moine, L.; Tsapis, N. End-Chain Fluorination of Polyesters Favors Perfluorooctyl Bromide Encapsulation into Echogenic PEGylated Nanocapsules. Polym. Chem. 2017, 8 (16), 2559-2570.

(20) Berlepsch, H. v.; Böttcher, C.; Skrabania, K.; Laschewsky, A. Complex Domain Architecture of Multicompartment Micelles from a Linear ABC Triblock Copolymer Revealed by Cryogenic Electron Tomography. Chem. Commun. 2009, 0 (17), 2290.

707

(21) Skrabania, K.; Laschewsky, A.; Berlepsch, H. v.; Böttcher, C. Synthesis and Micellar Self-Assembly of Ternary Hydrophilic-Lipophilic-Fluorophilic Block Copolymers with a Linear PEO Chain. Langmuir 2009, 25 (13), 7594-7601.

(22) Skrabania, K.; Berlepsch, H. v.; Böttcher, C.; Laschewsky, A. Synthesis of Ternary, Hydrophilic-Lipophilic-Fluorophilic Block Copolymers by Consecutive RAFT Polymerizations and Their Self-Assembly into Multicompartment Micelles. Macromolecules 2010, 43 (1), 271-281.

(23) Kaberov, L. I.; Verbraeken, B.; Hruby, M.; Riabtseva, A.; Kovacik, L.; Kereïche, S.; Brus, J.; Stepanek, P.; Hoogenboom, R.; Filippov, S. K. Novel Triphilic Block Copolymers Based on Poly(2-Methyl-2Oxazoline)- Block -poly(2-Octyl-2-Oxazoline) with Different Terminal Perfluoroalkyl Fragments: Synthesis and Self-Assembly Behaviour. Eur. Polym. J. 2017, 88, 645-655.

(24) Kaberov, L. I.; Verbraeken, B.; Riabtseva, A.; Brus, J.; Talmon, Y.; Stepanek, P.; Hoogenboom, R.; Filippov, S. K. Fluorinated 2-Alkyl-2-Oxazolines of High Reactivity: Spacer-Length-Induced Acceleration for Cationic Ring-Opening Polymerization As a Basis for Triphilic Block Copolymer Synthesis. ACS Macro Lett. 2018, 7 (1), 7-10.

(25) NIJENHUIS, A. J.; GRIJPMA, D. W.; PENNINGS, A. J. Lewis Acid-Catalyzed Polymerization of L-Lactide - Kinetics and Mechanism of the Bulk-Polymerization. Macromolecules 1992, 25 (24), 6419-6424.

(26) Spasova, M.; Mespouille, L.; Coulembier, O.; Paneva, D.; Manolova, N.; Rashkov, I.; Dubois, P. Amphiphilic Poly(D- or L-Lactide)-b-Poly(N,N-Dimethylamino-2-Ethyl Methacrylate) Block Copolymers: Controlled Synthesis, Characterization, and Stereocomplex Formation. 
(27) Zhao, Y.; Shuai, X.; Chen, C.; Xi, F. Synthesis of Star Block Copolymers from Dendrimer Initiators by Combining Ring-Opening Polymerization and Atom Transfer Radical Polymerization. Macromolecules 2004, 37 (24), 8854-8862.

(28) Li, H.; Gu, W. Y.; Li, L.; Zhang, Y. M.; Russell, T. P.; Coughlin, E. B. Synthesis of Semicrystalline/Fluorinated Side-Chain Crystalline Block Copolymers and Their Bulk and Thin Film Nanoordering. Macromolecules 2013, 46 (10), 3737-3745.

(29) Henderson, T. J. Quantitative NMR Spectroscopy Using Coaxial Inserts Containing a Reference Standard: Purity Determinations for Military Nerve Agents. Anal. Chem. 2002, 74 (1), 191-198.

(30) Diou, O.; Fattal, E.; Delplace, V.; Mackiewicz, N.; Nicolas, J.; Meriaux, S.; Valette, J.; Robic, C.; Tsapis, Imaging: Influence of Pre or Post-Functionalization on Capsule Morphology. Eur. J. Pharm. Scattering. J. Appl. Crystallogr. 2007, 40, 165-177.

(33) Koda, Y.; Terashima, T.; Sawamoto, M. Fluorinated Microgel Star Polymers as Fluorous Nanocapsules for the Encapsulation and Release of Perfluorinated Compounds. Polym. Chem.

(34) Koda, Y.; Terashima, T.; Sawamoto, M.; Maynard, H. D. Amphiphilic/Fluorous Random Copolymers as a New Class of Non-Cytotoxic Polymeric Materials for Protein Conjugation. Polym. Chem. 2015, $6,240-247$.

(35) Pisani, E.; Fattal, E.; Paris, J.; Ringard, C.; Rosilio, V.; Tsapis, N. Surfactant Dependent Morphology of Polymeric Capsules of Perfluorooctyl Bromide: Influence of Polymer Adsorption at the Dichloromethane-Water Interface. J. Colloid Interface Sci. 2008, 326 (1), 66-71. 
Morphology of Perfluorohexane Polymeric Microcapsules Intended as Ultrasound Contrast Agents. Int. J. Pharm. 2014, 471 (1-2), 10-17.

(37) Riess, J. G. Fluorous Micro- and Nanophases with a Biomedical Perspective. Tetrahedron 2002, 58 (20), 4113-4131.

(38) Krafft, M. P.; Riess, J. G. Chemistry, Physical Chemistry, and Uses of Molecular FluorocarbonHydrocarbon Diblocks, Triblocks, and Related Compounds-Unique "Apblar" Components for SelfAssembled Colloid and Interface Engineering. Chem. Rev. 2009, 109 (5), 1714-1792.

(39) Hillmyer, M. A.; Lodge, T. P. Synthesis and Self-Assembly of Fluorinated Block Copolymers. J. Polym. Sci. Part a-Polymer Chem. 2002, 40 (1), 1-8.

(40) Boissenot, T.; Fattal, E.; Bordat, A.; Houvenagel, S.; Valette, J.; Chacun, H.; Gueutin, C.; Tsapis, N. Paclitaxel-Loaded PEGylated Nanocapsules of Perfluorooctyl Bromide as Theranostic Agents. Eur. J. Pharm. Biopharm. 2016, 108, 136-144.

(41) Li, Z.; Kesselman, E.; Talmon, Y.; Hillmyer, M. A.; Lodge, T. P. Multicompartment Micelles from ABC Miktoarm Stars in Water. Science (80-. ). 2004, 306 (5693), 98-101.

(42) Krafft, M. P.; Riess, J. G. Perfluorocarbons: Life Sciences and Biomedical Uses - Dedicated to the Memory of Professor Guy Ourisson, a True RENAISSANCE Man. J. Polym. Sci. Part a-Polymer Chem. 2007, 45 (7), 1185-1198.

(43) Riess, J. G. Highly Fluorinated Amphiphilic Molecules and Self-Assemblies with Biomedical Potential. Curr. Opin. Colloid Interface Sci. 2009, 14 (5), 294-304.

(44) Zaggia, A.; Ameduri, B. Recent Advances on Synthesis of Potentially Non-Bioaccumulable Fluorinated Surfactants. Curr. Opin. Colloid Interface Sci. 2012, 17 (4), 188-195.

(45) Barmentlo, S. H.; Stel, J. M.; van Doom, M.; Eschauzier, C.; de Voogt, P.; Kraak, M. H. S. Acute and Chronic Toxicity of Short Chained Perfluoroalkyl Substances to Daphnia Magna. Environ. Pollut. 2015, 198, 47-53.

(46) Kirkpatrick, C. J.; Otto, M.; Van Kooten, T.; Krump, V.; Kriegsmann, J.; Bittinger, F. Endothelial Cell Cultures as a Tool in Biomaterial Research. J. Mater. Sci. Mater. Med. 1999, 10, 589-594. 
778 (47) Hughes, M. S.; Marsh, J. N.; Hall, C. S.; Fuhrhop, R. W.; Lacy, E. K.; Lanza, G. M.; Wickline, S. A. Acoustic Characterization in Whole Blood and Plasma of Site-Targeted Nanoparticle Ultrasound Contrast Agent for Molecular Imaging. J. Acoust. Soc. Am. 2005, 117 (2), 964.

781

782

783

784

785

786

787

788

789

(48) Couture, O.; Bevan, P. D.; Cherin, E.; Cheung, K.; Burns, P. N.; Foster, F. S. Investigating Perfluorohexane Particles with High-Frequency Ultrasound. Ultrasound Med. Biol. 2006, 32 (1), 73-82.

(49) de Jong, N.; Ten Cate, F. J.; Lancée, C. T.; Roelandt, J. R. T. C.; Bom, N. Principles and Recent Developments in Ultrasound Contrast Agents. Ultrasonics 1991, 29 (4), 324-330.

(50) Sarrazin, B.; Tsapis, N.; Mousnier, L.; Taulier, N.; Urbach, W.; Guenoun, P. AFM Investigation of Liquid-Filled Polymer Microcapsules Elasticity. Langmuir 2016, 32 (18). 

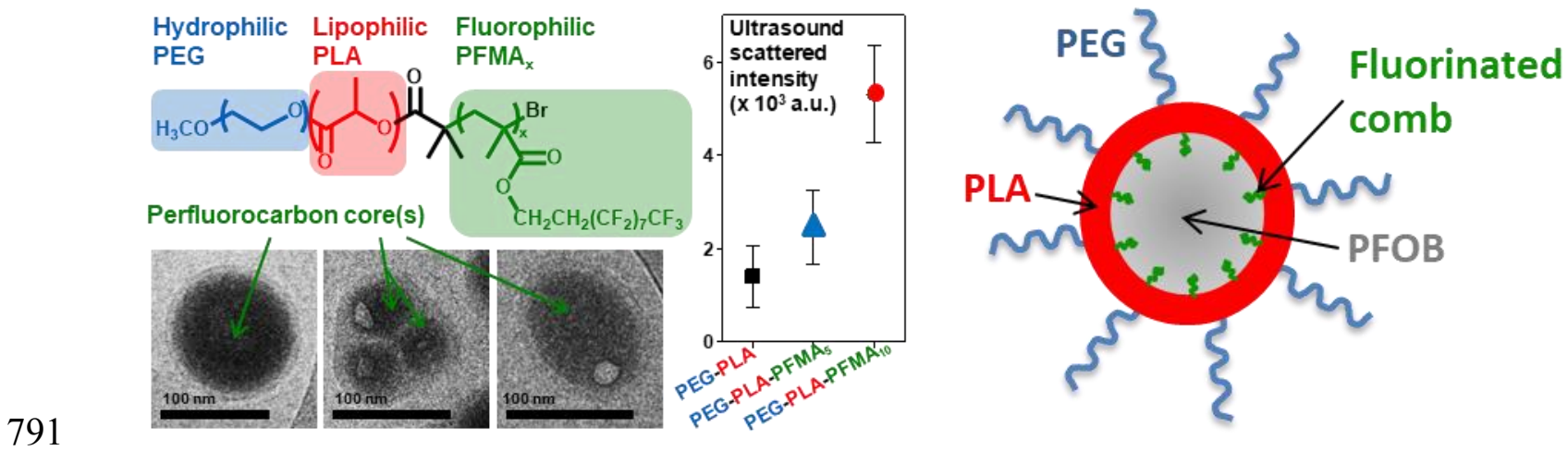